\title{
Polar vortex evolution during Northern Hemispheric winter 2004/05
}

\author{
T. Chshyolkova ${ }^{1}$, A. H. Manson ${ }^{1}$, C. E. Meek ${ }^{1}$, T. Aso ${ }^{2}$, S. K. Avery ${ }^{3}$, C. M. Hall ${ }^{4}$, W. Hocking ${ }^{5}$, K. Igarashi $^{6}$, \\ C. Jacobi ${ }^{7}$, N. Makarov ${ }^{8}$, N. Mitchell ${ }^{9}$, Y. Murayama ${ }^{6}$, W. Singer ${ }^{10}$, D. Thorsen ${ }^{11}$, and M. Tsutsumi ${ }^{2}$ \\ ${ }^{1}$ Institute of Space and Atmospheric Studies, University of Saskatchewan, 116 Science Place, Saskatoon, SK, S7N 5E2, \\ Canada \\ ${ }^{2}$ National Institute of Polar Research, Tokyo, Japan \\ ${ }^{3}$ CIRES, University of Colorado, Boulder, USA \\ ${ }^{4}$ Troms $\varnothing$ Geophysical Observatory, University of Troms $\varnothing$, Troms $\varnothing$, Norway \\ ${ }^{5}$ Department of Physics and Astronomy, University of Western Ontario, London, Canada \\ ${ }^{6}$ National Institute of Information and Communications Technology, Tokyo, Japan \\ ${ }^{7}$ Institute for Meteorology, University of Leipzig, Leipzig, Germany \\ ${ }^{8}$ Institute for Experimental Meteorology, SPA “Typhoon”, Obninsk, Russia \\ ${ }^{9}$ Centre for Space, Atmospheric, and Oceanic Sciences, Department of Electronic and Electrical Engineering, University of \\ Bath, Bath, UK \\ ${ }^{10}$ Leibniz-Institut fur Atmospharen physik an der Universitat Rostock, Kühlungsborn, Germany \\ ${ }^{11}$ Department of Electrical and Computer Engineering, University of Alaska, Fairbanks, USA
}

Received: 20 February 2007 - Revised: 28 May 2007 - Accepted: 12 June 2007 - Published: 29 June 2007

\begin{abstract}
As a part of the project "Atmospheric Wave Influences upon the Winter Polar Vortices $(0-100 \mathrm{~km})$ " of the CAWSES program, data from meteor and Medium Frequency radars at 12 locations and MetO (UK Meteorological Office) global assimilated fields have been analyzed for the first campaign during the Northern Hemispheric winter of 2004/05. The stratospheric state has been described using the conventional zonal mean parameters as well as Q-diagnostic, which allows consideration of the longitudinal variability.

The stratosphere was cold during winter of 2004/05, and the polar vortex was relatively strong during most of the winter with relatively weak disturbances occurring at the end of December and the end of January. For this winter the strongest deformation with the splitting of the polar vortex in the lower stratosphere was observed at the end of February. Here the results show strong latitudinal and longitudinal differences that are evident in the stratospheric and mesospheric data sets at different stations. Eastward winds are weaker and oscillations with planetary wave periods have smaller amplitudes at more poleward stations. Accordingly, the occurrence, time and magnitude of the observed reversal of the zonal mesospheric winds associated with stratospheric disturbances depend on the local stratospheric conditions. In general, compared to previous years, the winter of 2004/05 could be characterized by weak planetary wave activity at stratospheric and mesospheric heights.
\end{abstract}

Correspondence to: T. Chshyolkova

(t.sch@usask.ca)
Keywords. Meteorology and atmospheric dynamics (Middle atmosphere dynamics; Waves and tides) - Radio science (Remote sensing)

\section{Introduction}

The stratospheric polar vortex, a system of strong eastward winds, is the main dynamical feature of the winter middle atmosphere $(20-100 \mathrm{~km})$ at middle and high latitudes. Each day after the autumnal equinox less sunlight reaches the polar stratosphere, and as a consequence, the primary heating due to ozone decreases. As a result of the radiational cooling at high latitudes a strong negative temperature gradient develops between polar and tropical regions. This leads to the formation of the polar night jet, comprising strong eastward winds encircling the pole. These winds reach speeds of $\sim 80 \mathrm{~m} / \mathrm{s}$ at $\sim 60 \mathrm{~km}$ altitude in the Northern Hemisphere $(\mathrm{NH})$ and isolate polar air (the core of the polar vortex) from air in the tropics and middle latitudes (Schoeberl and Hartmann, 1991; Wallace and Hobbs, 2006). Therefore the polar vortex not only dominates the dynamics, it also has a profound effect on the distribution of chemical constituents.

At mesospheric heights, due to gravity wave (GW) drag, the eastward wind speeds decrease and eventually become westward at the lower thermospheric levels (Holton, 1983; Lindzen, 1981). This GW drag also drives the mean meridional circulation at these heights and the associated

Published by Copernicus Publications on behalf of the European Geosciences Union. 
downward motion at higher latitudes is responsible for a much warmer mesopause and even stratopause than would be expected from considerations of radiative equilibrium.

The NH polar vortex is highly variable throughout its life cycle. Intervals of a strong vortex (symmetrical and centered over the pole) with high wind speeds are interrupted by sudden stratospheric warmings (SSW). During SSW stratospheric temperatures significantly increase (at least $25 \mathrm{~K}$ per week) at higher latitudes $\left(>50^{\circ}\right)$. The stratospheric warming is called major (MSW) if the temperature enhancement leads to reversal of the middle latitude-to-pole temperaturegradient and results in reversal of the mean zonal winds from eastward to westward at heights near $30 \mathrm{~km}$. Usually a MSW develops in the middle of winter, after the solstice. If there is no reversal of the mean zonal circulation then the stratospheric warming is called minor. The warming that occurs in late winter/early spring, and marks the transition from winter to summer circulation, is the final warming. There is also one more type of warming, the so-called Canadian warming, which occurs as a result of intensification of the Aleutian anticyclone with a reversal of the temperature gradient poleward of $60^{\circ} \mathrm{N}$ over Canada.

Labitzke (1972) investigated temperature changes in the middle atmosphere at higher latitudes (circa $65^{\circ} \mathrm{N}$ ), during stratospheric warmings, using satellite radiance and rocket measurements. The results indicated that the effects of stratospheric mid-winter warmings extend into the upper mesosphere. It was shown that at first the temperature increases around $60 \mathrm{~km}$ height. Then over several days the middle stratosphere warms up, while the lower stratosphere and upper mesosphere cool. During the breakdown of the vortex, temperatures rise in the lower stratosphere and upper mesosphere and decrease in the layer between 30 and $60 \mathrm{~km}$.

At mesospheric heights reversals of the dominating eastward winds have been observed in association with stratospheric disturbances (Gregory and Manson, 1975; Greisiger et al., 1984; Jacobi et al., 1997; Hoffmann et al., 2002). Hoffmann et al. (2002) studied the response of the mesospheric winds, which were measured with Medium Frequency (MF) radars, to stratospheric circulation disturbances at Juliusruh $\left(55^{\circ} \mathrm{N}\right)$ during $1989-2000$ and at Andenes $\left(69^{\circ} \mathrm{N}\right)$ during 1998-2000. Reversals of mesospheric winds were observed on days near those of stratospheric warmings and of enhanced activity of quasi-stationary waves. However, clear coincidences between stratospheric and mesospheric events occurred only for planetary-scale phenomena. It was also noted that wind reversals occurred at different times at the two stations, with the later reversal at the more poleward station (Andenes). Some cases, when the mesospheric zonal winds decreased and/or reversed during cold stratospheric condition, were reported as well (Greisiger et al., 1984).

Another European study (Jacobi et al., 2003) involved mesospheric radar wind measurements over Castle Eaton $\left(52^{\circ} \mathrm{N}\right)$, Collm $\left(52^{\circ} \mathrm{N}\right)$ and Esrange $\left(68^{\circ} \mathrm{N}\right)$ during the February 2001 major stratospheric warming. They also found that the warming resulted in a reversal of both the zonal and meridional wind components. Earlier, Jacobi et al. (1997) had argued that although the beginning of the warming at low stratospheric heights $(\sim 20 \mathrm{~km})$ often appears simultaneously with the weakening or reversal of the mesospheric zonal winds $(\sim 90 \mathrm{~km})$, this is not the result of large vertical scale or wavelength process, but is rather due to the fact that the warming needs approximately the same time to reach the lower stratosphere and the mesosphere from the stratopause, where it starts. Both Hoffmann et al. (2002) and Jacobi et al. (2003) observed long period oscillations around 10 and 20 days in their radar data. The 20-day spectral peak was assumed to be merely the response time of the MLT winds to the stratospheric warming, while the 10-day spectral peak could have been the signature of a planetary wave propagating from below. Therefore the variability at the mesospheric heights could be the result of the combined effect of a vertically propagating planetary wave and decreasing zonal winds, i.e. a trend rather than an oscillation. Manson et al. (2002) using both radar winds and airglow intensities during the SSW and final warmings of several winters, found no relationship between these events and phases of the long period oscillations associated with planetary waves.

During the same stratospheric warming event (February 2001) that had been studied by Jacobi et al. (2003), hydroxyl $(\sim 86 \mathrm{~km})$ and oxygen green line $(\sim 97 \mathrm{~km})$ emissions were measured using a ground-based wide angle Michelson Interferometer at Resolute Bay, Canada $\left(75^{\circ} \mathrm{N}, 95^{\circ} \mathrm{W}\right)$. Winds obtained by Doppler-shifting techniques from both emission layers showed reversals around the times of SSW (Bhattacharya et al., 2004). Spectral analyses of the data indicated that during the periods of cold or undisturbed stratospheric temperatures the amplitudes of oscillations with periods from $6 \mathrm{~h}$ to 2 days decreased. The authors also noted an increase in short $(<12 \mathrm{~h})$ period oscillations over the course of the warming.

The generally accepted mechanism of SSW (Matsuno, 1971) assumes that tropospherically forced planetary waves propagate upward, where they decelerate the mean zonal flow as they dissipate, and through related enhanced poleward and subsequently downward motion initiate a stratospheric warming. Due to the increase of the wave amplitude with altitude, the deceleration of the eastward flow becomes stronger with height until at a certain level (50-75 km) waveinduced deceleration may reverse the wind flow. This creates a critical level at which planetary waves are absorbed and temperature disturbances may be large. Intense warming is expected at and below the critical level in the poleward region with cooling (that is smaller than the warming in magnitude) above the critical level due to adiabatic descent and ascent, respectively. It was also shown that at lower latitudes the temperatures decrease below the critical level and may increase slightly above it. Then, due to breaking and dissipation of planetary waves near the critical level, the winds increase in the westward direction and the critical level shifts 
downward. The region of warm temperatures at high latitudes starts to descend.

The model (Matsuno, 1971) predicts a decrease in temperature above the critical level at high latitudes, which is much smaller than the increase beneath it. Holton (1983) argued that cooling due only to adiabatic ascent near the critical level is not enough to explain the observed decrease of mesospheric temperatures during the SSW, especially when the critical level descends to the lower heights. Using a numerical model with a simple GW spectrum the author demonstrated that a significant temperature decrease in the mesosphere resulted. This was caused by a reduction of the mean poleward meridional circulation due to a decrease of the GW drag followed by a relaxation toward radiative equilibrium. The decrease of GW drag was considered to be a result of the changed propagation conditions for GW in the lower atmosphere during the course of a SSW event.

More recently Liu and Roble (2002) carried out a numerical study of the impact of a self-generated stratospheric warming on the Mesosphere/Lower Thermosphere (MLT) region. The Thermosphere, Ionosphere, Mesosphere, and Electrodynamics General Circulation Model/Climate Community Model (TIME-GCM/CCM3), which is a new generation GCM with GW parameterization, was used. They showed that growth of the planetary wave with the zonal wave number $\mathrm{m}=1$ precedes the SSW, and that this growth could be due to wave resonance. The resonant amplification of the wave causes the deceleration and reversal of the zonal wind and induces poleward and downward (the latter at high latitudes) circulation in the stratosphere and equatorward circulation in the lower mesosphere. These lead to the adiabatic warming in the polar stratosphere $(<25 \mathrm{~K})$ and strong cooling $(\sim 40 \mathrm{~K})$ in the lower mesosphere. The authors (Liu and Roble, 2002) also demonstrated that changes in the wind field alter the propagation conditions for gravity waves (GW), so that more eastward GW can reach the MLT region during the warming, where they can cause weakening and eventual reversal of the newly formed westward jet. The resulting vertical gradient of the winds is consistent with a cool polar mesosphere. The dissipation of GW at mesospheric heights may also generate planetary waves in situ (Smith, 1996).

The CAWSES program (Climate and Weather of the Sun Earth System; SCOSTEP 2004-08) has offered more collaborative opportunities to study the winter polar vortices, in particular the strong longitudinal differences that are evident in wind measurements from different stations, i.e. the occurrence, time and magnitude of the reversals of the zonal mesospheric winds (Smith et al., 1982). For the project "Atmospheric Wave Influences upon the Winter Polar Vortices (0$100 \mathrm{~km}$ )", wind data from several radars at 12 mid- and highlatitude locations and global assimilated fields from a GCM have been analyzed for the first campaign during the Northern Hemispheric winter of 2004/05. Data and their analyses are described in Sects. 2 and 3, respectively. The evolution of the stratospheric vortex over the Arctic during the winter is presented in Sect. 4, while Sect. 5 deals with the issue of stratosphere-mesosphere coupling. Section 6 provides a summary.

\section{Data}

\subsection{Radar data}

To study dynamics at the mesospheric heights $(60-100 \mathrm{~km})$ the meridional (NS) and zonal (EW) components of the winds obtained by Medium (MF) and Very High Frequency (VHF) radars are used. The daily mean wind data from selected heights were provided by $12 \mathrm{mid}$ - and high-latitude stations. The coordinates of the stations, main parameters and references that contain more detailed description of these radars are given in Table 1.

All MF radars are of similar configuration; they employ the spaced antenna technique to detect motions of weakly ionized irregularities in the ionospheric D and lower $\mathrm{E}$ regions. To estimate wind velocities from the raw data, two different methods, the spaced antenna "full correlation analysis" by Meek (1980) and a more classical analysis by Briggs (1984), were used. Thayaparan et al. (1995) compared winds calculated using these two methods and found no significant difference between them.

Meteor radars detect the part of transmitted energy that is scattered back by the meteor's trail of ionized gas. Then the atmospheric wind velocities are deduced by observing how the meteor trail drifts with time (Doppler shifting). All of the meteor radars (except Obninsk) are commercially produced HF/VHF All-Sky Interferometric Meteor Radars by ATRAD (Atmospheric Radar Systems Pty Ltd, Australia) or MARDOC (Modular Antenna Radar Designs Of Canada) together with Genesis Software Pty, Ltd (SKiYMET). These VHF allsky systems employ interferometric techniques and operate at very high pulse repetition frequencies $(\sim 2 \mathrm{kHz})$. Such frequencies allow the determination of additional meteor parameters such as entrance speeds. Description of the hardware, detection algorithms and data handling can be found in the paper by Hocking et al. (2001).

Both meteor and MF radars provide horizontal winds in the MLT region. However, they employ different measurement techniques, use different assumptions for the wind estimation, and have their own limitations. For example, the fields of view are approximately $\pm 17^{\circ}$ and $\pm 70^{\circ}$ for $\mathrm{MF}$ and VHF radars, respectively. There are also other parameters, such as signal-to-noise ratio and instrumental characteristics that can contribute to the discrepancies between observations. Several results on wind comparisons obtained by co-located MF and VHF systems have been published (Cervera and Reid, 1995; Thayaparan and Hocking, 2002; Hall et al., 2005). Although these studies employed different comparison techniques and radar systems installed at various 
Table 1. Characteristics of the radars.

\begin{tabular}{lllllll}
\hline Station & $\begin{array}{l}\text { Longitude, } \\
\text { deg. East }\end{array}$ & $\begin{array}{l}\text { Latitude, } \\
\text { deg. North }\end{array}$ & Radar type & $\begin{array}{l}\text { Frequency, } \\
\text { MHz }\end{array}$ & $\begin{array}{l}\text { Height, km } \\
\text { (height step) }\end{array}$ & References \\
\hline Collm & 13 & 51.3 & SKiYMET & 32.6 & $82-97(3)$ & Jacobi et al. (2005) \\
Andenes & 16 & 69.3 & MF (ATRAD) & 1.98 & $82-96(2)$ & Singer et al. (1997) \\
Svalbard & 16 & 78 & VHF (ATRAD) & 31 & $82-97(3)$ & Hall et al. (2003) \\
Tromsø & 19.7 & 69.3 & MF & 2.78 & $55-97(3)$ & Hall (2001) \\
Esrange & 20.4 & 67.9 & SKiYMET & 32.5 & $82-97(3)$ & Mitchell et al. (2002) \\
Obninsk & 36 & 52 & MWR beam & 33 & $\sim 94$ & Portnyagin et al. (2006) \\
Wakkanai & 142 & 45 & MF (ATRAD) & 1.9585 & $60-97(2)$ & Murayama et al. (2000) \\
Poker Flat & 212.5 & 65.1 & MF (ATRAD) & 2.43 & $60-97(2)$ & Hocking (2001) \\
Yellowknife & 245.5 & 62.5 & SKiYMET & 35.65 & $82-97(3)$ & Manson et al. (1973) and (2003) \\
Saskatoon & 252 & 52 & MF & 2.219 & $55-97(3)$ & Hocking (2001) \\
Platteville & 255 & 40 & MF & 2.219 & $55-97(3)$ & $82-97(3)$ \\
Resolute Bay & 265 & 74.5 & SKiYMET & 51.5 & & Har \\
\hline
\end{tabular}

locations (Australia, Canada, and Norway), the conclusions are similar. The mesospheric wind velocities as determined by meteor and MF radars demonstrate good agreement below $90 \mathrm{~km}$. In general the MF meridional wind speeds are systematically lower by $20 \%$, while the zonal component shows "modestly altitude-dependent" differences (Hall et al., 2005). It is necessary to keep this in mind when measurements from radars are considered below (Sect. 5).

\subsection{MetO data}

MetO (also known as UKMO, United Kingdom Meteorological Office) temperatures and horizontal wind components have been used to describe the state of the stratosphere. The MetO data are the result of assimilation of operational meteorological measurements from satellites, radiosondes, and aircraft into a numerical forecasting model of the stratosphere and troposphere. Since November 2000 the MetO fields have been produced using a 3-D variational (3DVAR) data assimilation system (Lorenc et al., 2000). After October 2003 the "New Dynamics" version of the "Unified Model" was introduced and three more levels (up to $0.1 \mathrm{hPa} \approx 64 \mathrm{~km}$ ) added to the existing 22 standard UARS (Upper Atmosphere Research Satellite) pressure levels. The outputs of the model with data assimilation are global fields of daily temperatures, geopotential heights and wind components. There are 72 latitudes and 96 longitudes with $2.5^{\circ}$ and $3.75^{\circ}$ steps in latitude and longitude, respectively.

Estimates of the errors in the analysed fields are $1^{\circ} \mathrm{K}$ and $6 \mathrm{~m} / \mathrm{s}$ at low heights $(<100 \mathrm{hPa})$. These estimations are from the documentation provided by the team of the Met Office through the British Atmospheric Data Centre (BADC, http://badc.nerc.ac.uk/). In general, the errors are predicted to be larger at high latitudes and at the uppermost levels. Intercomparisons of different climatological data sets for the middle atmosphere (UKMO, ECMWF, NCEP, CIRA86, etc.) reveal uncertainties and problem areas (Randel et al., 2004). The MetO data, for instance, show cold temperature-biases $(\sim 5 \mathrm{~K})$ near the stratopause (the upper levels of the model) and a warm tropical tropopause temperature $(\sim 1-2 \mathrm{~K})$. Note, however, that the data used for these comparisons were from earlier years (1992-1997), before later improvements in the model and assimilation technique. MetO data are widely used and shown to be very helpful in studies of the stratospheric region. In particular, O'Neill et al. (1994) successfully used the MetO data to study the evolution of the $\mathrm{NH}$ stratosphere during winter 1991/92. We have also used MetO data in conjunction with TOMS (Total Ozone Mapping Spectrometer) and MF radar data in earlier studies (Chshyolkova et al., 2005).

\subsection{Aura data}

As a supplement we have also employed temperatures measured by the Microwave Limb Sounder (MLS, Waters et al., 2006) on board the National Aeronautic and Space Administration (NASA) Aura satellite. The Aura spacecraft was launched on 15 July 2004 on a $705-\mathrm{km}$ sun-synchronous near-polar orbit with a 98.2 inclination. It has a 16-day "repeat cycle" and 233 revolutions per cycle. The temperatures used here are MLS data produced by the "version 1.5" data processing algorithms (along the measurement track). The daily data are available for the $316-0.001 \mathrm{hPa}(\sim 8-80 \mathrm{~km})$ altitude region and have coverage from $82^{\circ} \mathrm{S}$ to $82^{\circ} \mathrm{N}$ latitudes on each orbit with horizontal and vertical resolutions of $500 \mathrm{~km}$ and $4 \mathrm{~km}$, correspondently. The first validation results of Froidevaux et al. (2006) show that MLS measurements of temperature and mixing ratios of $\mathrm{O}_{3}, \mathrm{H}_{2} \mathrm{O}, \mathrm{N}_{2} \mathrm{O}$, $\mathrm{HCl}, \mathrm{HNO}_{3}$, and $\mathrm{CO}$ agree well with other satellite and meteorological datasets, as well as with balloon-measurements 
in the stratospheric and mesospheric regions. The precision of a single temperature profile was estimated to be $0.5-1 \mathrm{~K}$ in the middle stratosphere and noisier (estimated precision up to $2 \mathrm{~K})$ at the lowest $(316 \mathrm{hPa})$ and highest $(0.001 \mathrm{hPa})$ pressure levels. The special issue on Aura (IEEE Transactions on Geoscience and Remote Sensing 44(5), May 2006) offers more detailed information on the technical characteristics of the instrument and retrieval algorithms.

\section{Analysis}

To characterize the winter polar vortex the "Q-diagnostic" has been chosen and the algorithm developed by Harvey et al. (2002) was closely followed. The Q-diagnostic includes calculation of the scalar quantity $\mathrm{Q}$, the streamfunction $(\psi)$, the relative vorticity $(\zeta)$, and integration of $\mathrm{Q}, \zeta$, and winds along $\psi$ isopleths. Q is "a measure of the relative contribution of strain and rotation in the wind field" (Fairlie, 1995), and for two-dimensional flow it is given by

$$
\begin{aligned}
Q= & \frac{1}{2 a^{2}}\left\{\left(\frac{1}{\cos \varphi} \frac{\partial u}{\partial \lambda}-v \tan \varphi\right)^{2}+\left(\frac{\partial v}{\partial \varphi}\right)^{2}\right. \\
& \left.+2 \frac{\partial u}{\partial \varphi}\left(\frac{1}{\cos \varphi} \frac{\partial v}{\partial \lambda}+u \tan \varphi\right)\right\},
\end{aligned}
$$

where $\phi$ is latitude, $\lambda$ is longitude, $u$ is zonal wind, $v$ is meridional wind, and $a$ is the radius of the Earth. In areas where $Q$ is positive the strain dominates and fluid elements are stretched, and in regions with negative $Q$ rotation dominates the flow. For example, shear-zones beyond the edges of vortices and near jet streams have positive $Q$ while negative $Q$ is associated with stable rotational flow (Babiano et al., 1994) and is generally observed inside vortices. However, as was noted by Harvey et al. (2002), in the presence of elongated vortices (cyclonic and anticyclonic) and polar vortex divisions shear-zones can also be found inside vortices. Therefore, for identification of the vortex edges the integrated values of $Q$ along streamfunction lines are used. Those streamlines that have $\oint Q \approx 0$ and the strongest integrated winds are chosen to represent the vortex "edges". The integration of relative vorticity along the streamlines enables one to distinguish cyclonic and anticyclonic vortices. A more detailed description of the Q-diagnostic can be found in Fairlie (1995) and Harvey et al. (2002), and references therein.

\section{Evolution of the polar vortex during winter of 2004/05}

The NH winter of 2004/05 was relatively cold, especially in the lower stratosphere. More days and larger areas with temperatures below $195 \mathrm{~K}$ were observed during this Arctic winter (Manney et al., 2006). Due to decreases in temperature, a reduction of up to $\sim 0.5 \mathrm{ppmv}$ in water vapor was detected over Spitsbergen in the $\sim 12-20 \mathrm{~km}$ height region on $25-27$ January due to ice formation (Jiménez et al., 2006). Figure 1
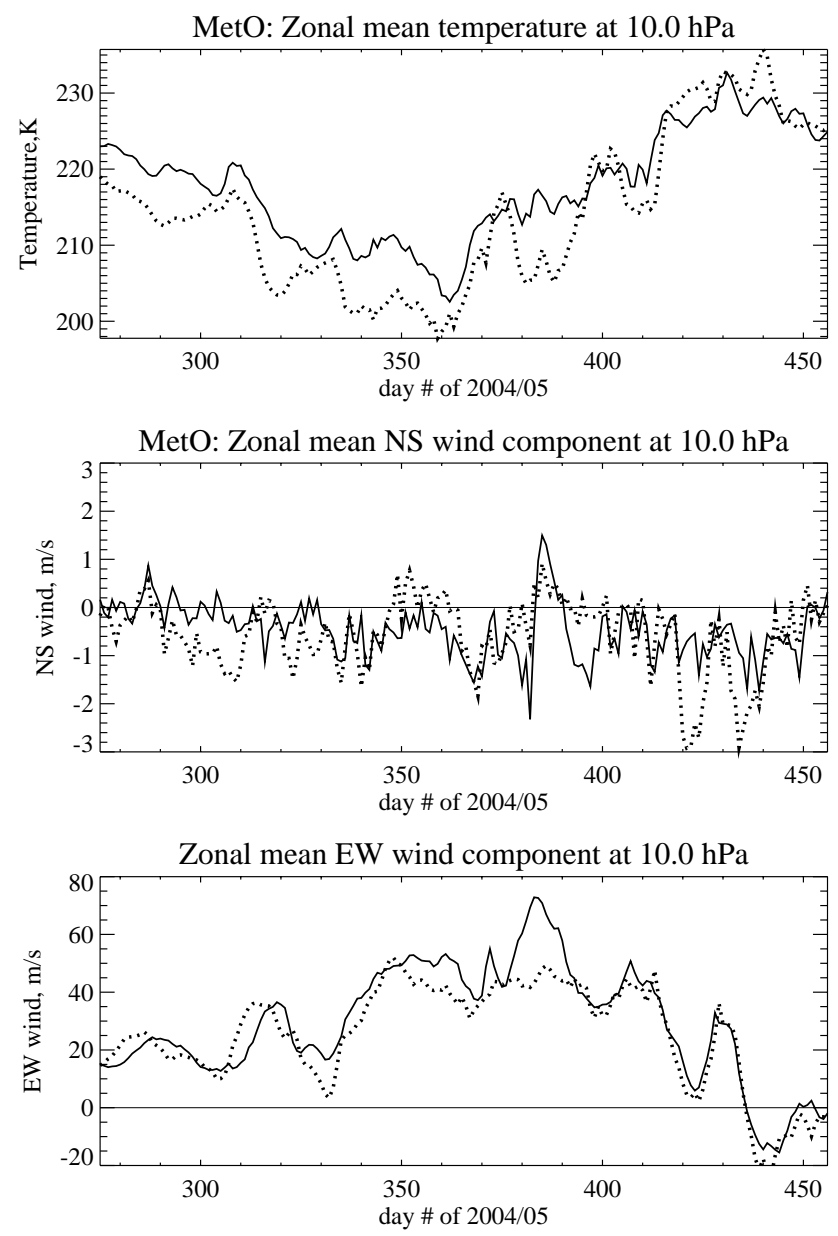

Fig. 1. Temperature (top), NS (middle) and EW (bottom) wind components from MetO $10 \mathrm{hPa}$ level averaged along the $60^{\circ} \mathrm{N}$ (solid) and $70^{\circ} \mathrm{N}$ (dashed) longitudinal circles for the time interval from 1 October 2004 till 31 March 2005 (day numbers 275-456).

shows variations of MetO temperatures (top panel), meridional (NS, middle panel) and zonal (EW, bottom panel) wind components averaged around the $60^{\circ} \mathrm{N}$ (solid line) and $70^{\circ} \mathrm{N}$ (dotted line) latitudinal circles at the $10 \mathrm{hPa}$ pressure level $(\sim 32 \mathrm{~km})$, for the time interval from October 2004 (starting from day number 275) until the end of March 2005 (day number 456). The MetO temperatures (top) decrease until the end of December (day number 366) down to $202 \mathrm{~K}$ and $180 \mathrm{~K}$ at $60^{\circ} \mathrm{N}$ and $70^{\circ} \mathrm{N}$, respectively, and exhibit similar temporal variations at both latitudes, with temperatures averaged over $70^{\circ} \mathrm{N}$ being lower than those averaged over $60^{\circ} \mathrm{N}$. Starting in January the temperatures have positive trends increasing up to $\sim 225 \mathrm{~K}$ in March. During the second part of the winter, zonal mean temperatures at $70^{\circ} \mathrm{N}$ demonstrate larger oscillations and occasionally exceed the zonal mean temperatures at $60^{\circ} \mathrm{N}$. The meridional component of the wind (middle panel) is weak and directed mostly equatorward. The zonal component of the wind increases (becomes 

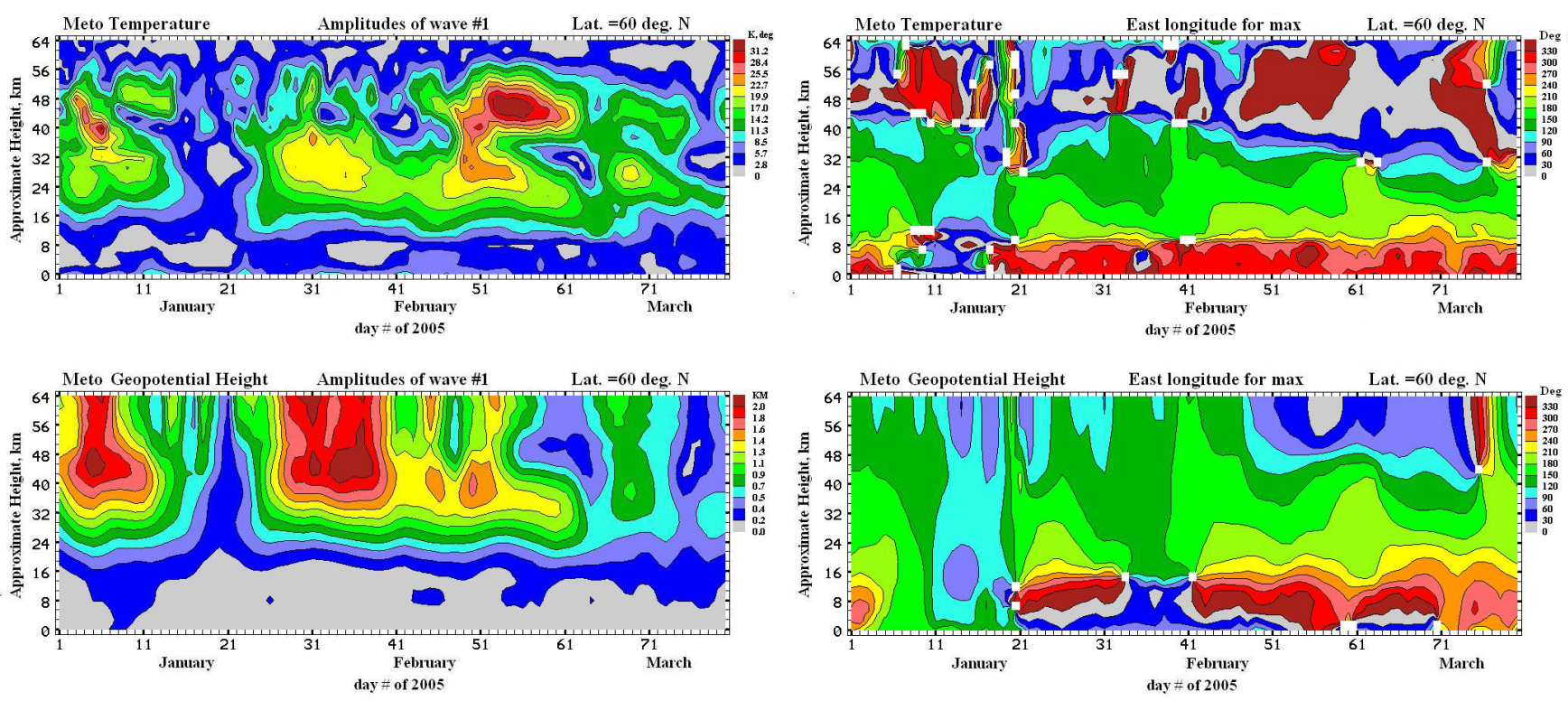

Fig. 2. Time (January-March) versus height $(\sim 0-64 \mathrm{~km})$ contours of the amplitudes (left) and phases (right) of the wave number 1 temperature (top) and geopotential height (bottom) perturbations. The phase is defined as longitude (east of Greenwich meridian) of the wave maximum.

more eastward) as winter proceeds with the strongest winds (up to 70 and $55 \mathrm{~m} / \mathrm{s}$ at $60^{\circ} \mathrm{N}$ and $70^{\circ} \mathrm{N}$, respectively) in December and January. After that, zonal winds decrease and become westward in the second part of March; this is the transition toward the summer-like circulation.

The absence of significant temperature increases in Fig. 1 (more than $25 \mathrm{~K}$ over a week) and associated reversals of the zonal winds indicates that the winter of 2004/05 was cold and without midwinter major sudden warmings (MSW). However, there are several time intervals when the MetO temperatures exhibit rapid increases; for example, at the end of December/beginning of January (between day numbers 360 and 375), at the end of January/beginning of February (between day numbers 390 and 400), and at the end of February (between day numbers 410 and 425). During these timeintervals the zonal mean temperatures rise $\left(\sim 20 \mathrm{~K}\right.$ at $\left.70^{\circ} \mathrm{N}\right)$, zonal winds decelerate, and meridional winds become southward. This is likely due to the heat and momentum deposition by the planetary waves as the result of their interaction with the mean flow (Shepherd, 2000).

Usually, stratospheric disturbances are associated with the enhanced activity of the quasi-stationary waves as well as transient planetary waves. Characteristic of the quasistationary planetary waves with zonal wave numbers $m=1$ (SPW1) and $\mathrm{m}=2$ (SPW2) have been obtained by applying Fourier transform to MetO data for the time interval from 1 January to 31 March 2005. The amplitudes (left) and phases (the eastward longitude of the wave maximum, right) of the SPW1 calculated using temperature and geopotential height fields at latitude of $60^{\circ} \mathrm{N}$ are shown in Fig. 2 at the top and bottom panels, respectively. Although both parameters show peaks in amplitude of the wave during the previously mentioned intervals of interest, the characteristics of the peaks are quite different. The amplitude of the wave $m=1$ in geopotential height grows from the tropopause upward, maximizing $(\sim 2 \mathrm{~km})$ above $\sim 40 \mathrm{~km}$. Its first two peaks are strongest compared to the weak increase at the end of February. In contrast, the amplitudes of the wave $m=1$ in the temperature field show increases between 32 and $40 \mathrm{~km}$ during the first two intervals and at $48 \mathrm{~km}$ at the end of February, with the last peak being the strongest $(\sim 30 \mathrm{~K})$ among them. The wave phases change gradually clockwise (westward) with height from $\sim 360^{\circ}$ in the troposphere to $210-150^{\circ}$ in the lowermiddle stratosphere, and near zero in the upper stratosphere. Although below $\sim 40 \mathrm{~km}$ the phase tendencies are similar for both perturbations, in temperature and geopotential height, in the upper stratosphere the phase of the temperature-wave changes faster. Around the day of maximum warming (day number 61, end of February/beginning of March) the lines of constant phase for the temperature-wave coalesce near $32 \mathrm{~km}$, i.e. there is a very rapid phase change, while below that height the gradient is very small. The phases for the geopotential height wave (Fig. 2, bottom right) also change slowly with height up to $\sim 40 \mathrm{~km}$ during this time. It is worth noting that this vertical phase structure for temperature closely resembles that calculated by Liu and Roble (2002) for the wave number one of the geopotential height perturbation (their Fig. 6a). The maximum amplitudes of the wave number $\mathrm{m}=2$ (not shown) are smaller (about half the size) and are located between peaks (in the time domain) of the wave $m=1$ 


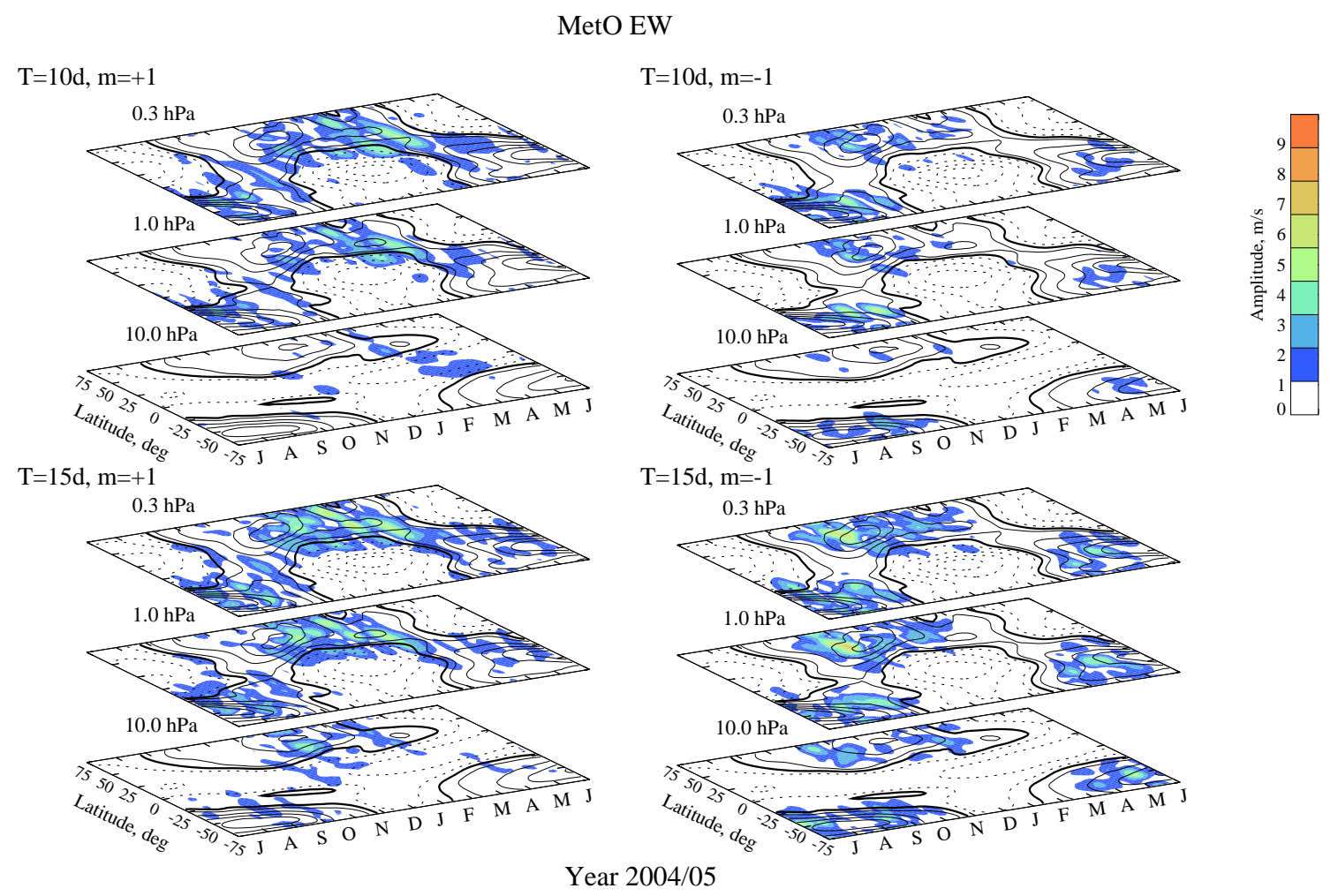

Fig. 3. The amplitudes of the MetO EW wind oscillations with periods 10 (the upper row) and 15 (the bottom row) days and westward/eastward wave numbers $+/-1$ versus latitude are shown for the time interval from July 2004 until June 2005. The mean zonal EW winds smoothed over 30 day intervals with 5 day step are contoured by solid (positive, eastward) and dashed (negative, westward) lines. The thick line is the "zero wind" line. The other contours are $\ldots-30,-10,+10,+30 \ldots \mathrm{m} / \mathrm{s}$.

for the first part of the winter. However, the last enhancements of the two waves, in late February, coincide.

The amplitudes for several horizontally propagating oscillations (PW) with different periods (T) and zonal wave numbers $(\mathrm{m})$ were calculated from MetO zonal winds using the least-square fitting process. Figure 3 demonstrates the amplitudes of eastward $(\mathrm{m}=-1)$ and westward $(\mathrm{m}=+1)$ propagating waves with periods 10 and 15 days for three heights 10 , 1 and $0.3 \mathrm{hPa}$. As discussed in (Chshyolkova et al., 2006), the eastward waves are baroclinic and westward are normal modes (Andrews et al., 1987). The solid and dashed lines indicate eastward and westward zonal mean winds, which are smoothed over 30-day intervals with a 5-day time-step. The thick solid line is the "zero-wind" line, and the step between contours is $10 \mathrm{~m} / \mathrm{s}$. Notice that the winter months of the $\mathrm{NH}$ are in the middle of each rectangle. It is seen from the figure that in the $\mathrm{NH}$ the eastward waves are more active in the beginning of the winter when the eastward mean winds are strongest, and are confined to the winter hemisphere (eastward background flow). Activity of the westward waves of the NH increases by the end of the winter, and they penetrate to the SH in March. In October the cross-hemispheric coupling of the westward waves is somewhat smaller than in the Arctic spring (March). Compared to winters of 2000 and
2001 , the amplitudes of the waves are $\sim 1.5$ times weaker this year (Chshyolkova et al., 2006).

To study the longitudinal variabilities of the polar vortex, the $\mathrm{Q}$ values have been calculated from MetO data at 24 isentropic surfaces (from 300 to $2000 \mathrm{~K}$ ) for each day of the $\mathrm{NH}$ winter of 2004/05 (1 November 2004-31 March 2005) using the Eq. (1) given in Sect. 3. The identified edges of vortices, as described in Sect. 3, have been used to color the cyclonic polar vortex with blue and anticyclones with orange; and then they are contoured as overlapping projections for isentropic surfaces from 500 to $2000 \mathrm{~K}(\sim 20-50 \mathrm{~km})$. The lowest isentropic surfaces were omitted as the existence of the tropospheric jet makes determination of the vortex edges difficult at those heights. The results are shown in Fig. 4 for four chosen days. The vortex for 25 December 2004 is a typical example of a cold vortex: the blue area has a coneshape reflecting the increase of the vortex area with height. On this day there were two relatively small anticyclonic areas located over Asia and the Atlantic Ocean. During most of the NH winter of 2004/05 the polar vortex exhibited similar characteristics except for three time intervals when it was disturbed (cf. Fig. 1). Two short-lived and weak disturbances occurred around 1 January and 1 February. The vortex became elongated and twisted with height. The anticyclones 

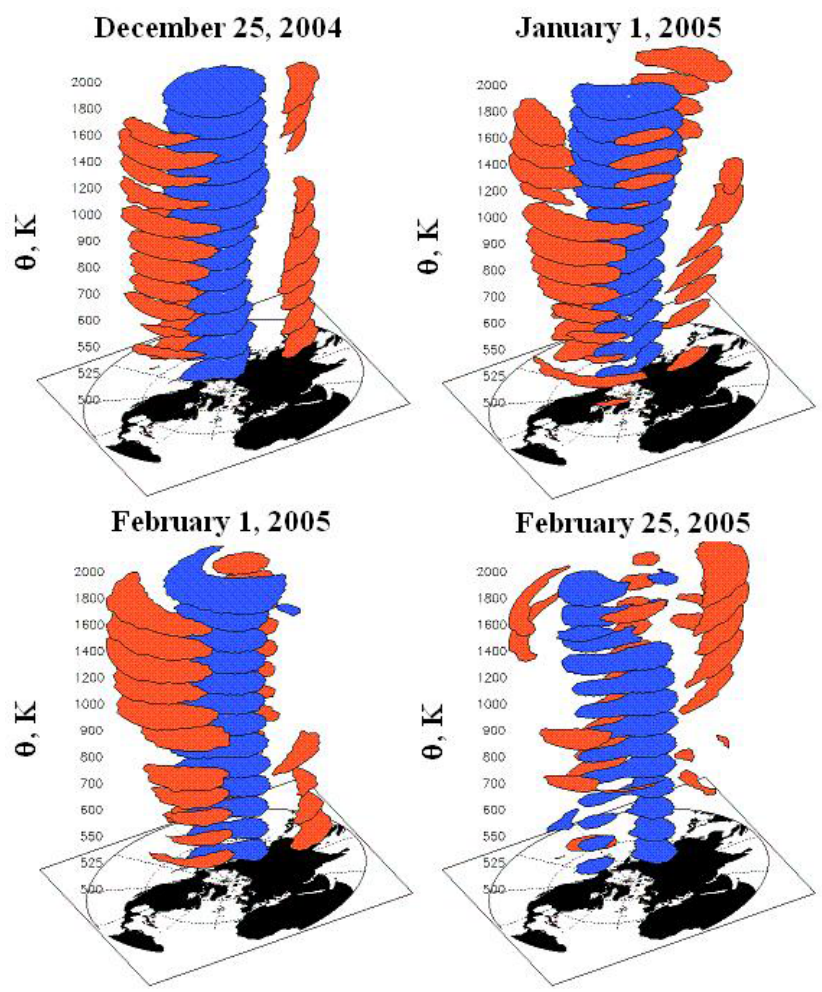

Fig. 4. Representation of the polar vortex (blue) and anticyclones (orange) from $\theta=500$ to $2000 \mathrm{~K}(\sim 20-50 \mathrm{~km})$ isentropic surface on 25 December 2004; 1 January, 1 February and 25 February 2005.

then occupied larger areas. The strongest disturbance for this winter occurred at the end of February. For example the vortex structure for 25 February is demonstrated in the bottom right corner of Fig. 4. In the lower stratosphere the polar vortex splits into two parts, while at the upper levels the vortex is just strongly elongated and displaced from the pole. Again, the whole structure is elongated and rotated westward with height.

Zonal asymmetry of the winter circulation is obvious during the disturbed days, but there are also longitudinal peculiarities when the vortex is relatively strong and circular. This is clearly seen from the comparison of the latitudealtitude cross-sections for $253^{\circ} \mathrm{E}$ (North America) and $16^{\circ} \mathrm{E}$ (Scandinavia-Europe) that are shown for 25 December 2004 (Fig. 5a) and for 25 February 2005 (Fig. 5b). These plots demonstrate the $Q$ parameter (dark/light grey shadings), "scaled" (see below) Potential Vorticity (PV, dot-dashed lines), and zonal winds (solid and dashed lines) for $20^{\circ} \mathrm{N}-$ $90^{\circ} \mathrm{N}$ latitudes and from 20 to $50 \mathrm{~km}$ heights. The areas dominated by rotation (negative $\mathrm{Q}$ values) are shaded with darker grey color. Eastward and westward winds are plotted using solid and dashed lines, respectively, and the thick solid lines denote the "zero-wind" line. The PV was modified by scaling it with a dimensionless factor, $(\theta / 420)^{-4}$, to remove altitudinal dependence due to the potential temperature $(\theta)$ changes with height (Müller and Günther, 2003, 2005).

The Arctic polar vortex is clearly visible as a region bounded by closely spaced dot-dashed lines (large gradients of scaled PV in Fig. 5); it is centered almost over the pole and occupies a large area (up to $\sim 40-50^{\circ} \mathrm{N}$ ). As can be seen in Fig. 5a, during December the cyclonic rotation is dominant over Europe (the top panel) at latitudes poleward of 55-60 with the maximum latitudinal gradients of PV also occurring near $55^{\circ}$. In contrast, over North America (the bottom panel) there is a zone of positive $Q$ ("shear zone") at $\sim 55^{\circ}$ between the central $\left(\sim 60-90^{\circ} \mathrm{N}\right)$ and mid-latitudinal $(40$ $50^{\circ} \mathrm{N}$ ) parts of the cyclonic vortex. Also notice the strong latitudinal gradients in PV near 40 and $55^{\circ}$ latitudes. Although the eastward winds demonstrate similarly very strong speeds $(\sim 90 \mathrm{~m} / \mathrm{s})$ near the "edge" of the vortex in both meridional cross-sections, positions of the maxima are different. Maximum winds are reached at $\sim 50^{\circ} \mathrm{N}$ over Europe and $\sim 40^{\circ} \mathrm{N}$ over the North American continent.

Figure $5 b$ shows that even more differences exist between European and North American locations on 25 February, during the strongest disturbance for this winter. At the North American longitude $\left(253^{\circ} \mathrm{E}\right)$ a westward wind cell centered near $70^{\circ}$ occupies the middle to high latitudes at stratospheric levels, and the eastward wind-jet is shifted equatorward (centered near $30^{\circ} \mathrm{N}$ ) and upward. At the same time, at the European longitude $\left(16^{\circ} \mathrm{E}\right)$, the eastward winds are still strong $(\sim 60 \mathrm{~m} / \mathrm{s})$ and maximize near $50^{\circ} \mathrm{N}$. This is due to the deformation and shift of the vortex away from the pole. The part of the vortex over North America weakened, while its second part over Europe was still strong.

\section{Stratosphere-mesosphere coupling}

In this section analysis of winds in the height region from $\sim 20$ to $97 \mathrm{~km}$ are discussed for 12 locations; this allows investigation of connections between stratospheric disturbances and mesospheric variability during winter 2004/05. Figure 6 shows zonal winds for altitudes between 0 and $97 \mathrm{~km}$ and for the time interval from October 2004 till March 2005 for six stations: Svalbard, Troms $\varnothing$, Collm, Resolute Bay, Yellowknife, and Saskatoon. The stations are divided in two groups: data from three Scandinavian-European and three Canadian radars are shown on the left and right sides of the figure, correspondingly. Each side is arranged so that the data from the most poleward stations are on the top and the most equatorward stations are on the bottom of the figure. Each plot consists of three altitudinal sections: $0-55 \mathrm{~km}, 55$ $80 \mathrm{~km}$, and $82-97 \mathrm{~km}$. The MetO daily zonal winds are presented at the lowest heights. Mean winds at the uppermost heights are from zonal winds measured by VHF (meteor) and MF radars, and obtained by the fitting of the mean, $24 \mathrm{~h}$ - and $12 \mathrm{~h}$-tides to the hourly radar measurements. The fitting uses a window of 3 days shifted by 1 day to optimize the quality 

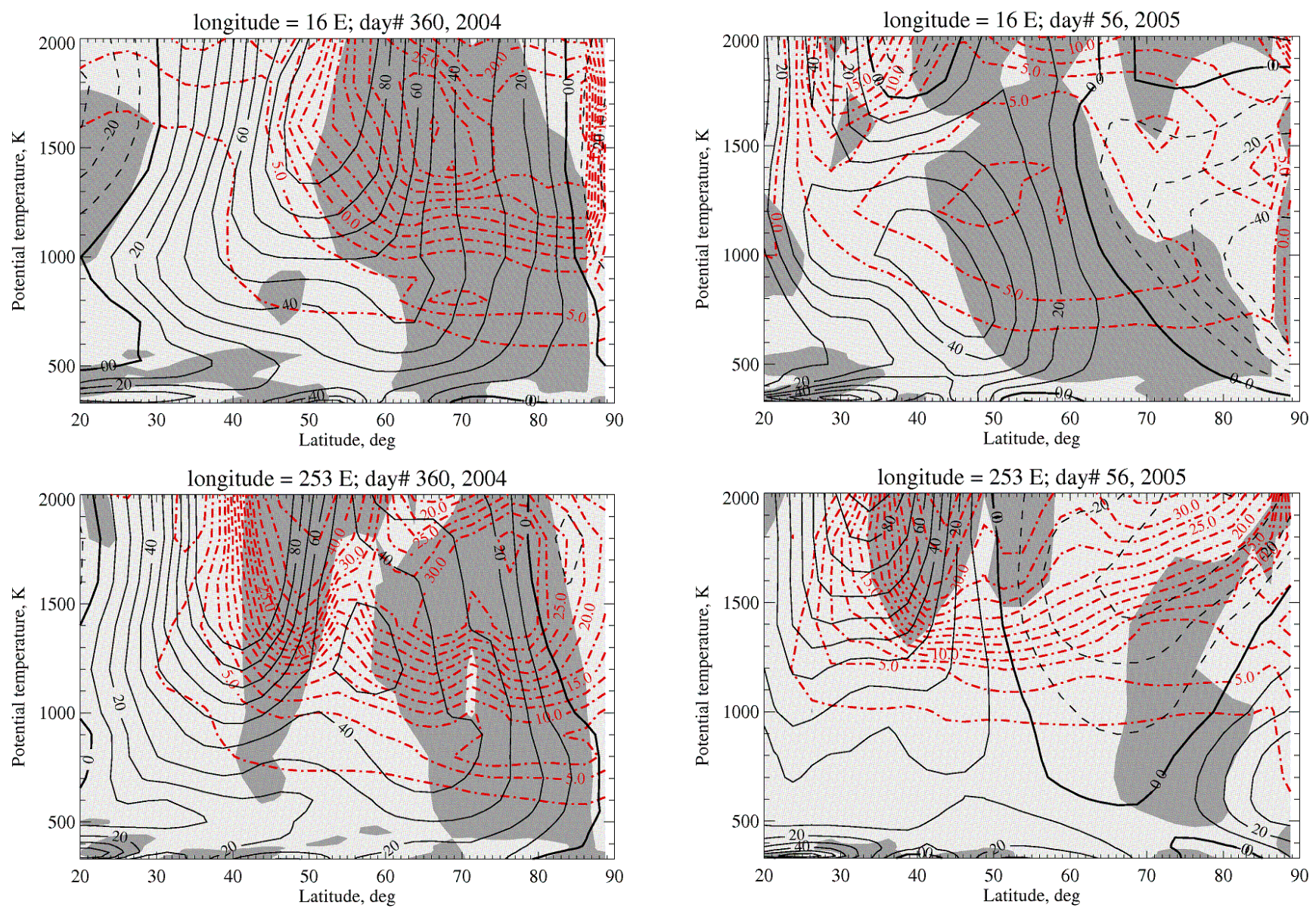

Fig. 5a. Latitude-altitude cross sections of the Q parameter (dark grey is negative, light grey is positive) at $16^{\circ} \mathrm{E}$ (top) and $253^{\circ} \mathrm{E}$ (bottom) longitudes on 25 December 2004 (day number 360). Solid and dashed lines are positive (eastward) and negative (westward) MetO zonal winds $(\mathrm{m} / \mathrm{s})$, respectively. Dash-dot lines are contours of modified PV (1PV unit $=10^{-6} \mathrm{~m}^{2} \mathrm{Ks}^{-1} \mathrm{~kg}^{-1}$ ).

of the means. For the sake of continuity, the middle altitudinal section shows daily winds calculated using the thermal wind equation with the MetO winds at the low boundary $(0.1 \mathrm{hPa})$. A simple linear fit was employed to calculate latitudinal temperature gradients from Aura MLS daily measurements within $\pm 10^{\circ}$ in latitude and $\pm 12^{\circ}$ in longitude over the stations.

The different datasets agree well near both their boundaries: 55 and $82 \mathrm{~km}$. Good agreement is expected around $55 \mathrm{~km}$ as we use MetO winds at its highest levels to begin the calculation of the wind field above $(55-80 \mathrm{~km})$. Around $\sim 82 \mathrm{~km}$ discrepancies can be found between winds calculated using thermal wind equation and radar measurements. There are several possible reasons for these discrepancies:

- There are unknown tidal signatures in Aura data. Two adjacent tracks $12 \mathrm{~h}$ apart have been used in calculations, so the 24-h tide is minimized, while contamina-

Fig. 5b. The same as Fig. 5a only for 25 February 2005 (day number 56).

tion due to the stronger 12-h tide at these latitudes could be significant. The radar winds $(82-97 \mathrm{~km})$ are "tidally corrected" (evidence for this is provided below).

- The thermal wind equation assumes geostrophic balance (no drag), which is rarely the case in the atmosphere. For example, at mesospheric heights the drag due to GW and PW is strong enough (e.g. Liu and Roble, 2002) to break this assumption. Without drag the zonal winds would continue to become more eastward throughout the $55-80 \mathrm{~km}$ height interval (Manson et al., 1991).

- The approach used to calculate temperature gradients may be too simple. For example, in general the zonal temperature gradients are smaller and do not strongly affect the results. However this assumption will not apply if a sharp boundary between cyclonic and anticyclonic vortices exists across a longitude range used for the radar station. Also the largest errors are expected for the stations located poleward of $\sim 72^{\circ} \mathrm{N}$ as the satellite 

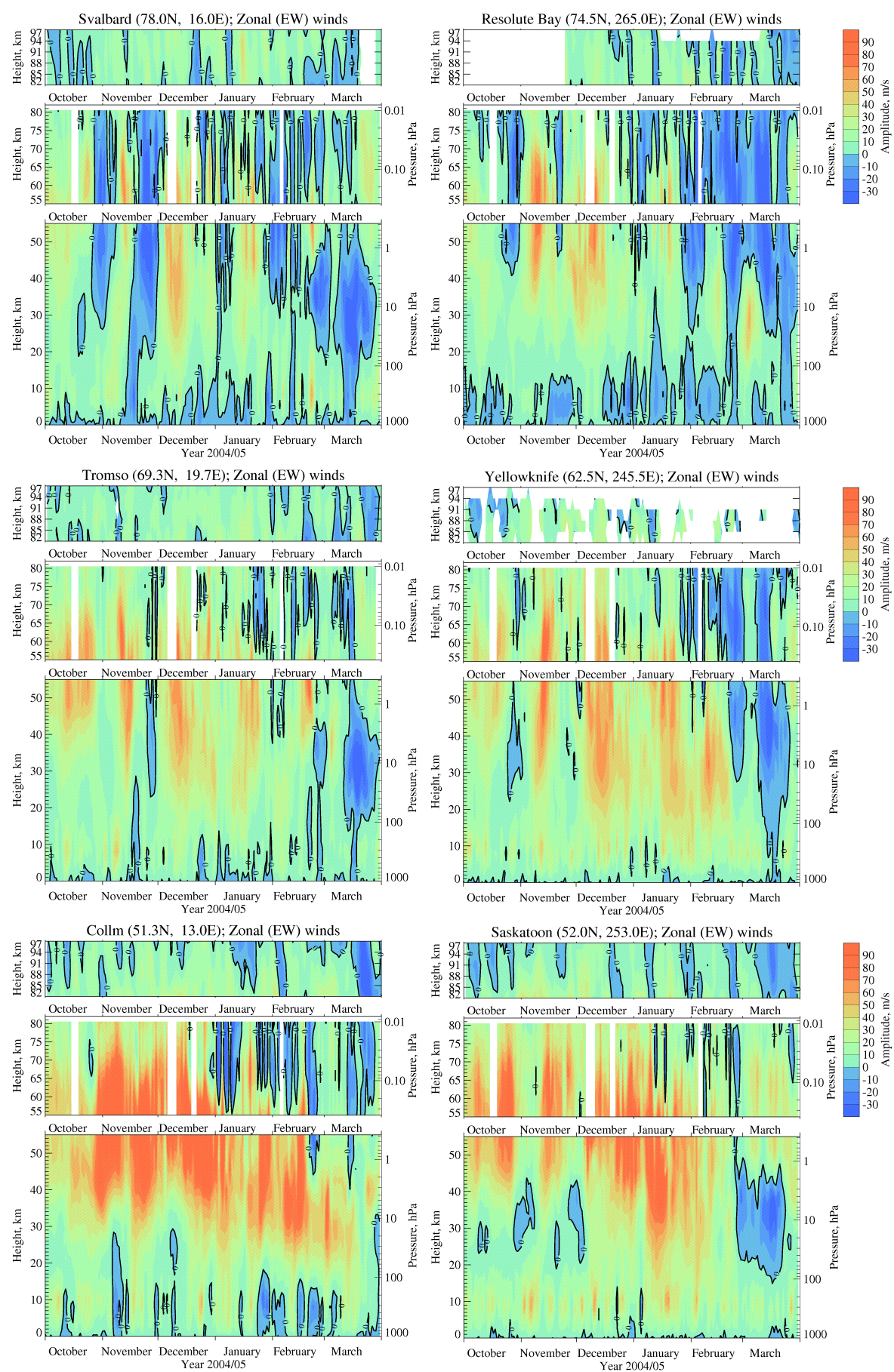

Fig. 6. Evolution of zonal winds in the height range from the surface up to the upper mesosphere $(97 \mathrm{~km})$ in the time interval from October 2004 until March 2005 for the Svalbard, Resolute Bay, Troms $\varnothing$, Yellowknife, Collm, and Saskatoon locations. The plot for each station consists of 3 parts: the MetO daily winds are shown in the bottom panel $(0-55 \mathrm{~km})$; the middle panel $(55-82 \mathrm{~km})$ is filled with daily winds obtained from the thermal wind equation using temperature gradients calculated from Aura MLS data; and mean winds obtained from the (mean + diurnal tide + semidiurnal tide) fit to the radar hourly measurements are used in the top panel (82-97 km). The fit uses a 3-day window shifted by 1 day. 


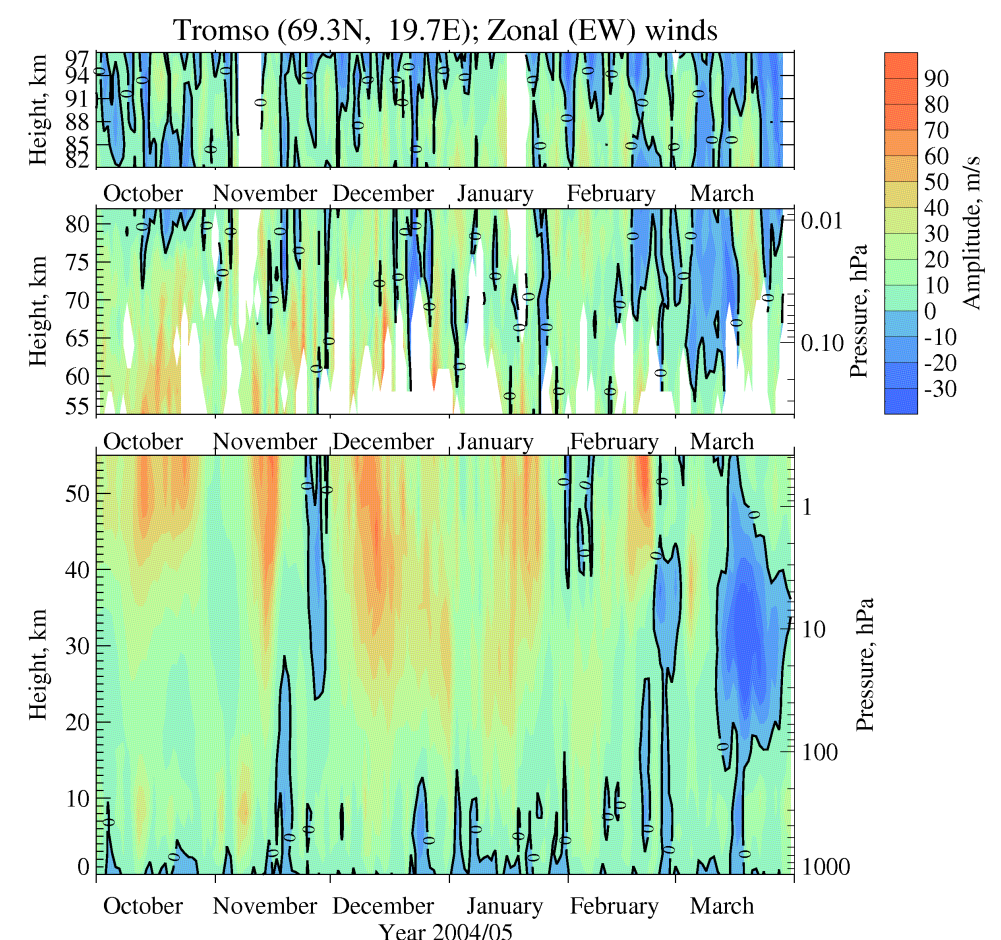

Saskatoon $(52.0 \mathrm{~N}, 253.0 \mathrm{E})$; Zonal (EW) winds
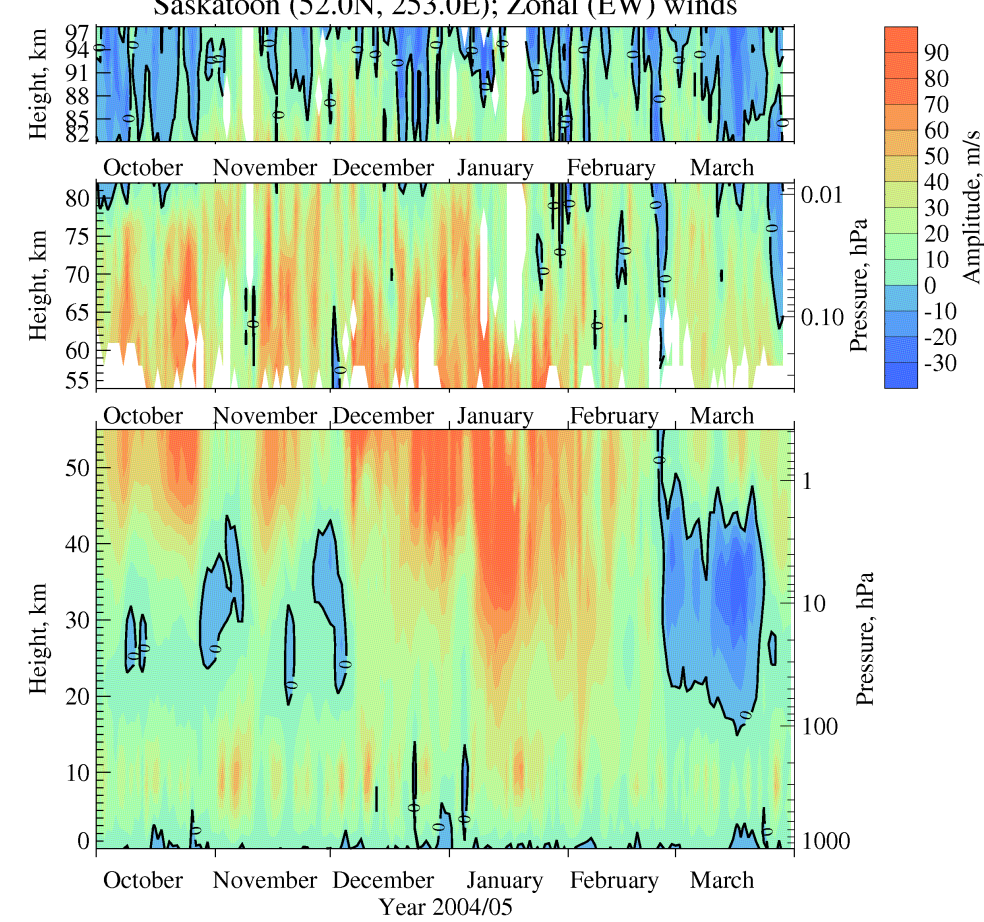

Fig. 7. Evolution of zonal winds in the height range from the surface of the Earth up to the upper mesosphere (97 km) in the time interval from October of 2004 until March of 2005 for Troms $\varnothing$ and Saskatoon. The MetO daily winds are shown in the bottom panel of each plot $(0-55 \mathrm{~km})$, while in the middle $(55-82 \mathrm{~km})$ and the top $(82-97 \mathrm{~km})$ panels day-time mean $(\geq 7 \mathrm{~h}$ of data) centred on noon and obtained from radar measurements are demonstrated. 
measurements only cover up to $82^{\circ} \mathrm{N}$. (An example of this is shown later in Fig. 8.)

- As was mentioned in Sect. 2.3, Aura MLS temperature data are less accurate at the upper levels $(0.001 \mathrm{hPa})$, although the MF radars have minimal zonal speed bias at $82 \mathrm{~km}$ (Sect. 2.1). Note also that there is a $2 \mathrm{~km}$ gap between the datasets.

- Data have different resolutions: 3 days in the 82-97 km and 1 day in the $55-82 \mathrm{~km}$ height regions.

The availability of the MFR data (Troms $\varnothing$, Saskatoon, and Platteville) at low heights allows comparisons between direct wind measurements and the winds calculated from the thermal wind equation. Figure 7 presents the zonal wind timealtitude cross-section for Troms $\varnothing$ and Saskatoon locations in a fashion similar to Fig. 6 . The lowest parts of the plots (0$55 \mathrm{~km})$ are the same in both figures and present the MetO assimilated daily zonal winds, while at the middle $(55-82 \mathrm{~km})$ and upper $(82-97 \mathrm{~km})$ heights the mean day-time winds are shown in Fig. 7. These winds were constructed from hourly data and with at least 7 values per day centered on noon. Usually, due to the increased noise level and lack of useful radar scatter during the night below $\sim 70 \mathrm{~km}$, the coverage is poorest at low heights, but becomes better near and above $80 \mathrm{~km}$, where the number of hourly mean values approaches 24 (Luo et al., 2002). The averaging over $7 \mathrm{~h}$ minimizes GW influences.

There is very good overall qualitative agreement between calculated and measured winds (middle panels) at all three stations (Platteville is not shown). The largest differences in the middle panel occur near $80 \mathrm{~km}$, where radar data often show westward (blue) winds. This can be attributed to tidal contamination. The comparison of the top panels in Figs. 6 and 7 for corresponding stations also reveals that the differences are mostly due to tides (the effect of different temporal resolution is insignificant). For example, for Saskatoon (Fig. 6, bottom left panel), in October the fitted mean winds (no tidal contamination) show westward cells closing at $\sim 82 \mathrm{~km}$, while in Fig. 7 (bottom plot) the westward winds penetrate below $\sim 80 \mathrm{~km}$. Again, remember to keep in mind that the thermal winds are available only up to $0.001 \mathrm{hPa}(\sim 80 \mathrm{~km})$, while the radars have no altitudinal gaps in this region. Another factor that would contribute to the discrepancies of Figs. 6 and 7 is the geostrophic assumption. The GW drag is important at the mesospheric heights and, as mentioned above, acts to decrease eastward winds. The geostrophic balance assumes zero drag, so the winds calculated using the thermal wind equation may be more eastward than the actual winds, especially at the upper levels. The smaller radar amplitudes could also be explained by the MF speed bias of $\sim 20 \%$ (Sect. 2.1). Despite all these differences the calculated thermal winds are a good approximation of the real winds in this height region and can be used for qualitative comparisons and wave analysis purposes.
Returning to consideration of Fig. 6, the main feature common to all stations is the eastward jet (green-red colors in Fig. 6) in the stratosphere-mesosphere height region (20$90 \mathrm{~km}$ ), which is often referred as the polar night jet (PNJ). The maximum of the eastward flow, which is located at $\sim 55$ $60 \mathrm{~km}$ in early winter, decreases in magnitude and progresses downward to $\sim 30-40 \mathrm{~km}$ with time. The magnitude of the PNJ varies throughout the winter with occasional reversals (blue) to the westward direction. After each disturbance, winds are restored to their normal winter values until they finally became westward throughout the middle atmosphere, marking the transition to the summer-like wind pattern. Although the general scenario is common for all stations, it differs in detail because the radars have different locations relative to the vortex. The eastward winds are weaker at higher latitudes as was also seen in Figs. 5a, b. The strong westward events seen at the high latitude Svalbard station below $\sim 85 \mathrm{~km}$ are much weaker at Troms $\varnothing$, and are seen only as relatively small decreases in eastward winds at Collm. Similar latitudinal differences can be seen for Canadian stations. Stations at Andenes, Esrange (not shown), and Troms $\varnothing$ are relatively close $(125-270 \mathrm{~km})$, and zonal wind time-variations at these stations are quite similar.

Longitudinal variations are apparent between Collm and Saskatoon (bottom plots in Fig. 6). The eastward winds are weaker at Saskatoon, which can be explained by the different location of the PNJ maximum over Europe and North America: $50^{\circ} \mathrm{N}$ for $16^{\circ} \mathrm{E}$ longitude and near $40^{\circ} \mathrm{N}$ for $253^{\circ} \mathrm{E}$ (Fig. 5). Indeed, the wind contours for Platteville (not shown) do exhibit much stronger eastward flows than at Saskatoon, which persist above $\sim 40 \mathrm{~km}$ throughout all winter until the end of March. Also, at the end of February (warming event) the transition to the westward winds occurred over Saskatoon between 20 and $97 \mathrm{~km}$, while at Collm the westward wind cell occupies the region between $\sim 40$ and $80 \mathrm{~km}$ for a few days, with eastward winds at heights near $30 \mathrm{~km}$ until the end of March. This reflects the vortex characteristics during this time (Sect. 4, bottom left plot in Fig. 4), and is consistent with Fig. 5b that shows weak westward winds at stratospheric levels for latitudes higher than $50^{\circ} \mathrm{N}$ (bottom plot) for Saskatoon longitudes, while there are still quite strong $(\sim 60 \mathrm{~m} / \mathrm{s})$ eastward winds over Europe at $50^{\circ} \mathrm{N}$ (top plot). Obninsk is located at a similar latitude, but is $\sim 20^{\circ}$ east of Collm. Zonal winds at Obninsk (not shown) are similar to those at Collm station, except they were less westward in the $55-82 \mathrm{~km}$ height range at the end of January/beginning of February. The meteor radar at Obninsk does not provide height information, and all reflections are assumed to be from the height region centered at approximately $94 \mathrm{~km}$. These winds and Collm winds at $94 \mathrm{~km}$ agree well, and have such similarities as wind reversals in the middle of January, the beginning of February, and in the middle of March.

It is also interesting to note that the wind profiles for Poker Flat and Wakkanai (not shown) are quite different from 
Scandinavian-European and Canadian stations. For example, the PNJ has stronger magnitudes at Poker Flat $\left(\sim 65^{\circ} \mathrm{N}\right)$ than at Canadian/European stations with similar latitudes. Over Wakkanai the first strong westward reversal occurred in the first half of January between 20 and $70 \mathrm{~km}$, and was followed by the second stronger reversal in February. Later the winds became weakly eastward above $\sim 40-50 \mathrm{~km}$, but remained westward in the lower stratosphere until the end of the March. These may be explained by the relatively close proximity of these stations to the Aleutian High.

Continuing with perusal of Fig. 6, in the upper mesospheric region $(82-97 \mathrm{~km})$ the eastward zonal winds decrease in magnitude with increasing height at all stations, although their particular variations differ. Most of their variability can probably be explained by the local effects of GWs on the mean flow (deceleration of the flow as well as induced variability with periods in the PW range, see for example Smith, 1996). Some of the reversals of the eastward mesospheric winds can be linked to the wind reversals below. The warming event at the end of February is the best example of such connection between mesosphere and stratosphere. The timing of such reversals appears to be approximately the same throughout the whole height range or sometimes a little earlier at the upper altitudes.

Next, an attempt to compare winds from the upper stratospheric $(\sim 50-60 \mathrm{~km})$ heights with those from the mesospheric heights $(82 \mathrm{~km})$ is made with the emphases on the vortex structure rather than consideration of eastward wind profiles at separate locations. The comparison is difficult mostly due to the lack of mesospheric observations. All available 3-day radar vectors were inspected. Days that indicated the usual winter cyclonic flow around the pole and events in February (1 and 19) were chosen for demonstration. In Fig. 8 the daily MetO winds at $2000 \mathrm{~K}(\sim 50 \mathrm{~km})$ isentropic surface (lower plots) along with the 3-day mean wind vectors $(82 \mathrm{~km})$ obtained at 12 radar stations (upper plots) are shown for 20 January, 1, 13, and 19 February 2005. The lower plots are the stereographic projections $\left(15-90^{\circ} \mathrm{N}\right)$ of the Q-diagnostic over the $\mathrm{NH}$ with the blue areas where $\mathrm{Q}$ is negative (rotation dominates the flow) and green areas where $\mathrm{Q}$ is positive (strain is dominant). Black arrows are winds, red stars are locations of the radar stations, and black/red lines are estimated edges of cyclones/anticyclones. Black filled dots are assigned to the areas with the negative PV, which are usual at low latitudes. Sometimes, however, the black dots can be found more poleward, which indicates an intrusion of the tropical air to the mid-latitudinal region at the upper stratospheric heights (Harvey et al., 2002). The vortex plots are daily, while the radar winds are obtained over 3-day interval centered on the chosen dates.

First of all at the upper stratospheric heights the vortex does not have the "solid" or continuous shape as it usually has in the middle stratosphere; at these levels patches of blue color are scattered over the hemisphere composing some kind of spiral or comma shapes. The meridional wind com- ponent is often strong, and there is, therefore, significant divergence from the cyclonic eastward flow. On the upper plots vectors of the mesospheric mean wind measured at 12 locations (the same locations that are shown by red stars on the lower plots) are placed on top of the stereographic map (30$90^{\circ} \mathrm{N}$ ). In January (e.g. 20 January, Fig. 8a) arrangement of radar wind vectors is consistent with cyclonic motion around the pole, and they match well the MetO winds at corresponding locations. Often, especially when negative areas of $\mathrm{Q}$ have consistent large circular shapes with little or no shear (green) zones inside, the stratospheric and mesospheric vectors show very close similarity in their directions. Usually best agreement requires a shift of the vortex with height, for example.

On 1 February (Fig. 8b), the time of the weak stratospheric disturbance, radar and MetO wind vectors over highlatitudinal stations $\left(>60^{\circ} \mathrm{N}\right)$ demonstrate opposite directions and have strong meridional components. This suggests an existence of strong thermal gradients of opposite directions at stratospheric and mesospheric heights. The MetO data at $\sim 30 \mathrm{~km}$ (not shown) indicate that the polar vortex was squeezed by two anticyclones located at lower latitudes in the $330-360^{\circ} \mathrm{E}$ and $90-180^{\circ} \mathrm{E}$ longitudinal sectors. The stronger of the two anticyclones $\left(90-180^{\circ} \mathrm{E}\right)$ also pushed the polar vortex away from the pole, which is reflected in Fig. 2 as amplitude of SPW1 increases at $60^{\circ} \mathrm{N}$. Therefore the boundary between cold and warm regions lay across the pole, and strong poleward/equatorward flows were established in the $30-60^{\circ} \mathrm{E}$ and $210-240^{\circ} \mathrm{E}$ longitudinal segments, respectively (Fig. 8b). At the upper heights (layer $50-80 \mathrm{~km}$ ) the Aura measurements (not shown) indicate reversed temperature gradients (cold in $120^{\circ} \mathrm{E}$ sector), so that winds at $\sim 80 \mathrm{~km}$, through thermal wind equation, now have opposite directions to the stratospheric winds. The winds were weak over Canadian stations (Platteville, Saskatoon, and Yellowknife), which are situated farther from this region of strong temperature gradients.

During the first half of February the stratospheric vortex became stronger. This is reflected in the plots for 13 February (Fig. 8c): the stratospheric and mesospheric winds are again similar in directions as was the case for most of January. On 19 February (Fig. 8d) the warming has begun and as in 1 February wind vectors have opposite directions at stratospheric and mesospheric heights over the European-Scandinavian sector. But this time the structure was more complicated and involved strong latitudinal as well as longitudinal temperature gradients. Aura data indicated warm temperatures over the pole, which resulted in SouthWestward wind directions at $82 \mathrm{~km}$ over Europe. Winds over Platteville, Saskatoon and Wakkanai, stations located in regions of the strong stratopause eastward jet, were not affected and had eastward directions at $82 \mathrm{~km}$, which is consistent with strong vortex conditions. For this day Aura temperature measurements did not show perfect alignment of opposite temperature gradients across the pole at stratospheric and 


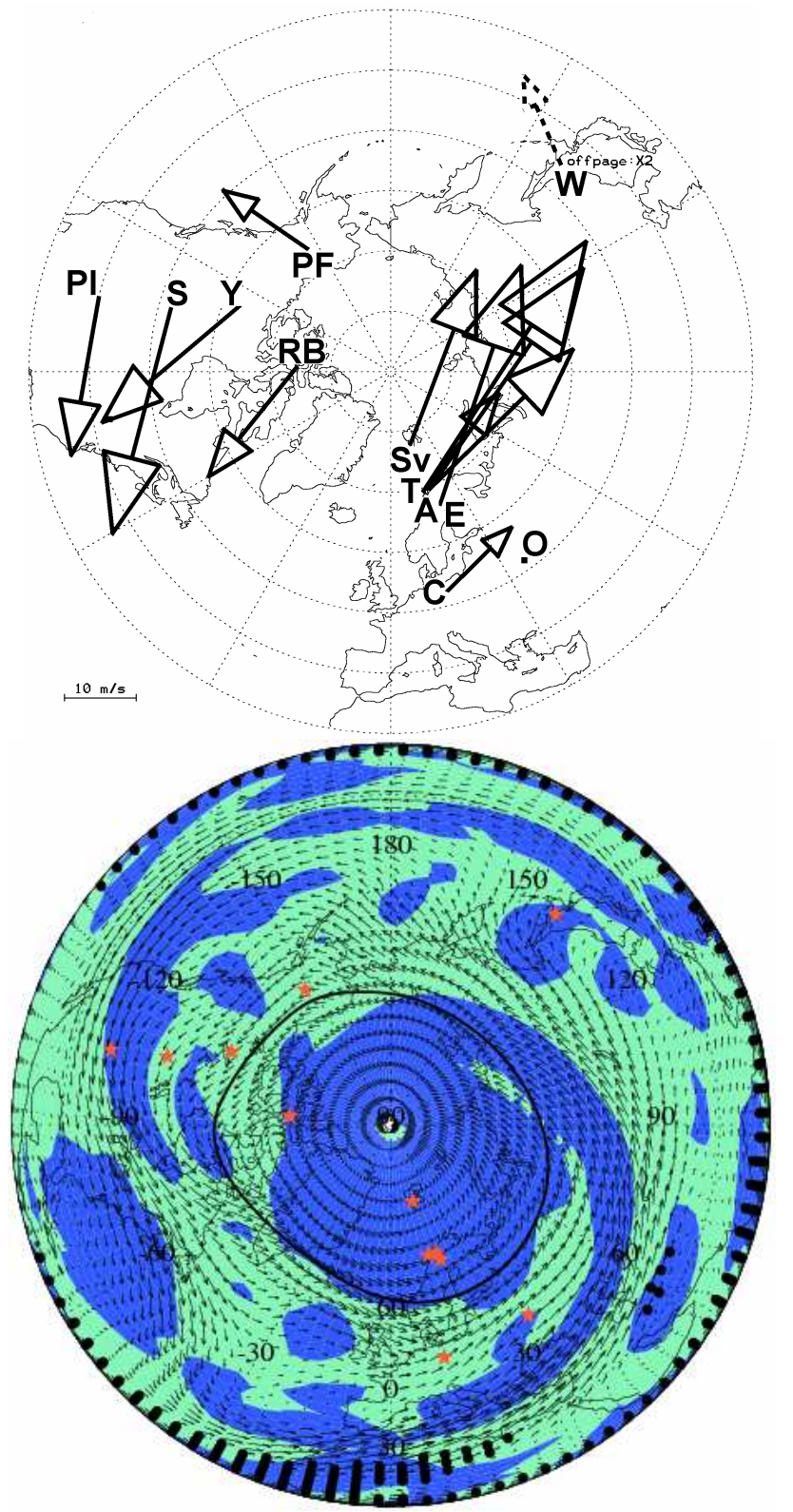

Fig. 8a. Evolution of the daily MetO winds (black arrows) at $2000 \mathrm{~K}$ isentropic surface (bottom) and 3-day mean winds obtained at 12 radar locations ( $82 \mathrm{~km}$, top) for 20 January 2005 . The dashed arrow indicates the speed is twice as big as that shown.

mesospheric heights, which can explain the more diverse relationships between stratospheric and mesospheric winds depending on the locations.

Finally by 25 February the vortex was split in two uneven parts at low stratospheric heights with the stronger part being over Europe (Fig. 4, bottom right). In the upper stratosphere (not shown) the vortex was deformed and twisted westward with height, so that the stronger cyclonic area was located over North America. At mesospheric heights (not shown)

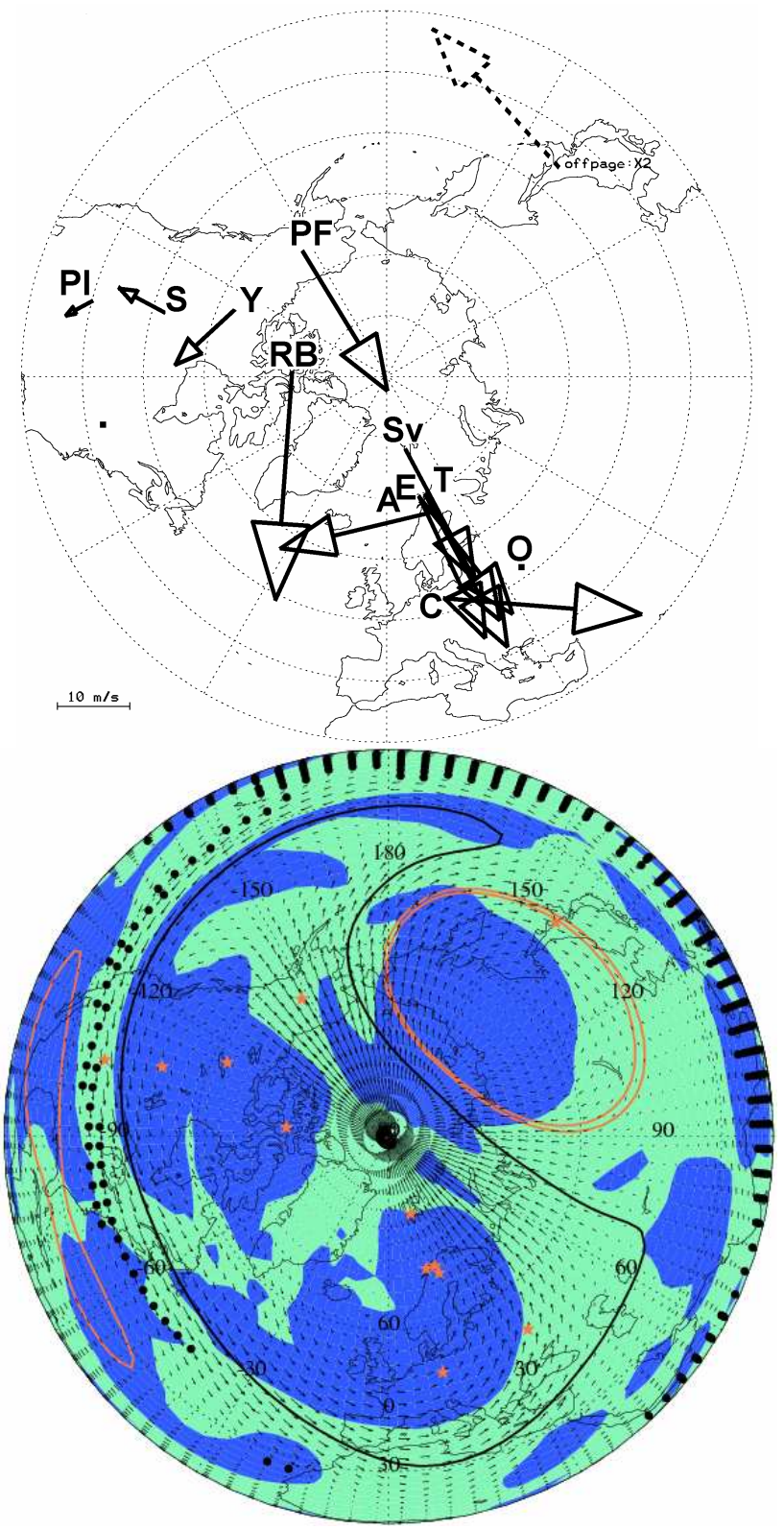

Fig. 8b. The same as Fig. 8a, but for 1 February 2005.

winds were also weak and completely disorganized. Later in March the cyclonic flow was partially restored at 50 and $82 \mathrm{~km}$, before it disappeared during the transition to the summer circulation.

The vector differences between mesospheric winds measured at $82 \mathrm{~km}$ and MetO assimilated winds at $\sim 64 \mathrm{~km}$ are shown in Fig. 9 for 3 months: December 2004, January and February 2005. The stations located near the center of the PNJ (Obninsk, Collm, Saskatoon and Platteville) consistently demonstrate strong westward (pointed to the left) vector differences, especially in December. The negative (angle of $\sim 180$ degrees) differences are consistent with the decrease 


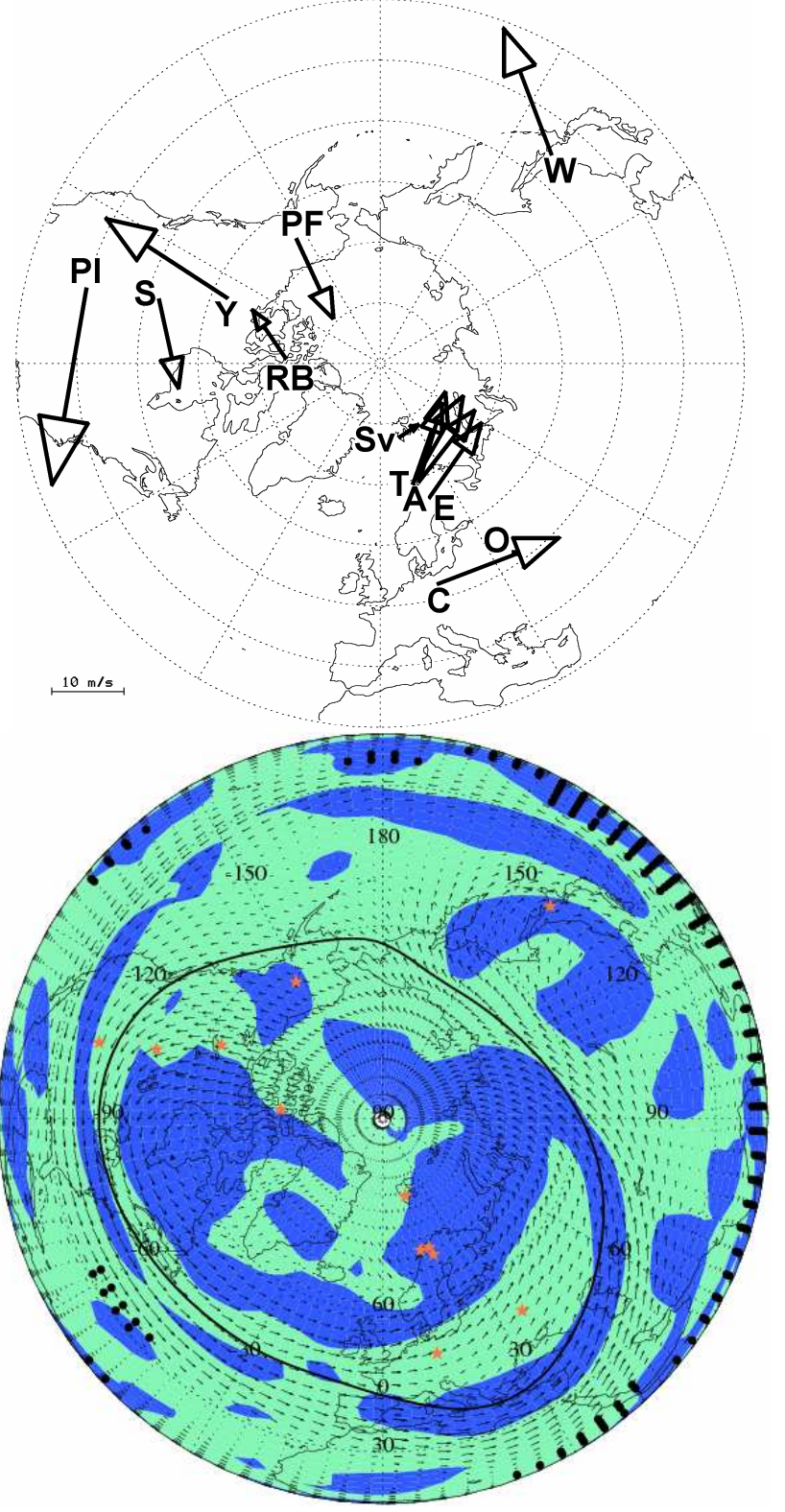

Fig. 8c. The same as Fig. 8a, but for 13 February 2005.

of the winds with height. This is in agreement, through the thermal wind equation, with a warm mesopause region, which is normal in winter. However at the end of February, during the strongest, for this winter, stratospheric disturbance the difference-vectors at these stations (except Platteville, a more equatorward station) are smaller or eastward (pointed to the right). This indicates weakening or reverse of the eastward flow in the stratopause.

Significant deviation of the illustrated strong differencevectors from the horizontal line (EW direction) implies reversed meridional flow between the $\sim 64 \mathrm{~km}$ and $82 \mathrm{~km}$ heights. The downward (in the figure) or southward direc-

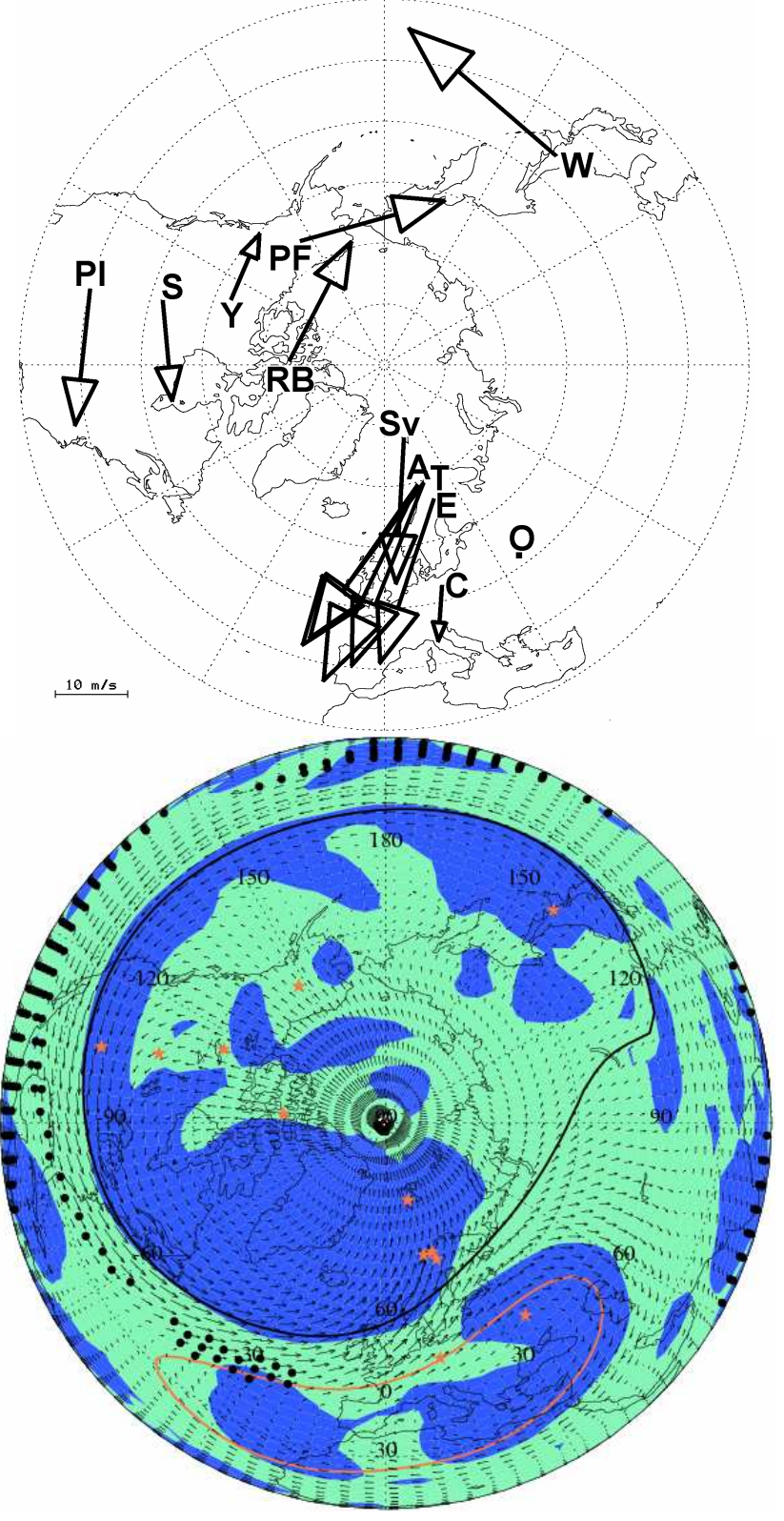

Fig. 8d. The same as Fig. 8a, but for 19 February 2005.

tions of the large difference-vectors indicate poleward flow at the stratopause levels and equatorward flow at the mesospheric levels, e.g. near 1 and 19 February. The reverse is true for the upward (northward) directions of the large differencevectors (e.g. early in December). Small vector differences normally occur when winds at both heights are in the same direction. All Scandinavian stations Esrange, Troms $\varnothing$, Andenes, and Svalbard lie inside the core of the vortex, and the angles of their difference-vectors change with time (generally from 180 to 270 degrees, except for one interval in the beginning of December) in a similar way. Although the highlatitude Canadian stations at Yellowknife and Resolute Bay 

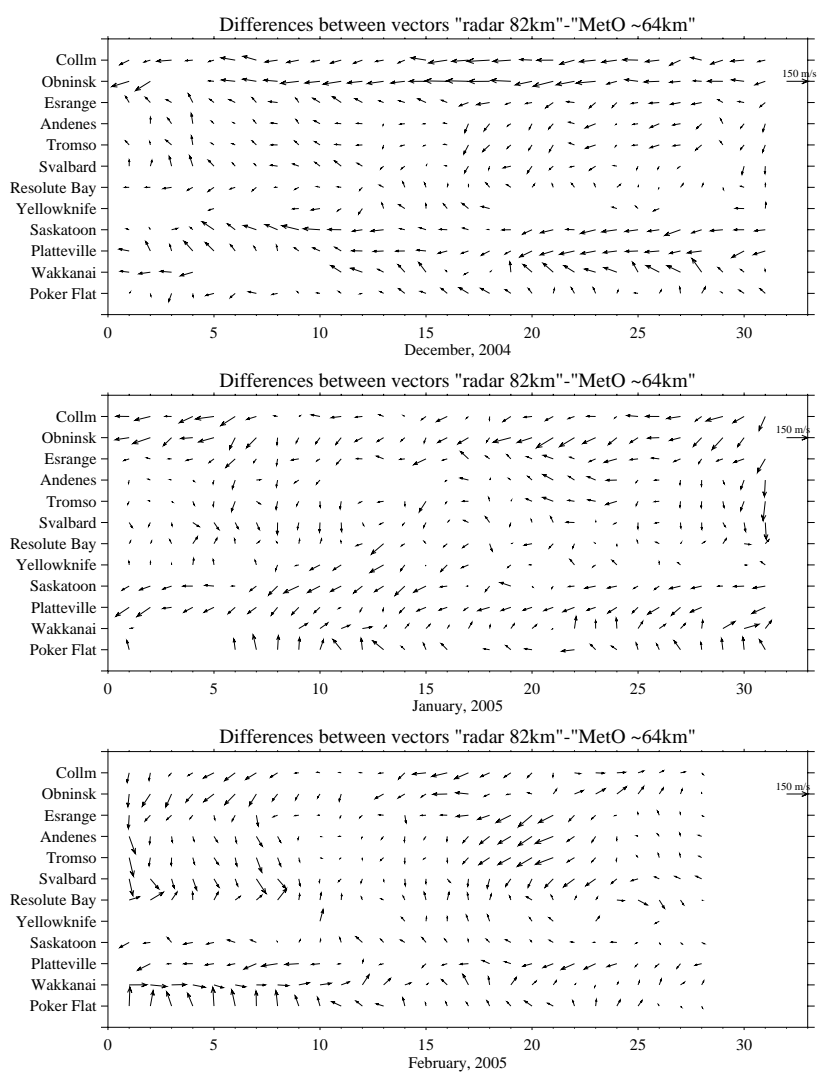

Fig. 9. Vectors of differences between radar winds measured at $82 \mathrm{~km}$ and MetO assimilated winds at $\sim 64 \mathrm{~km}$ for 3 months of winter of 2004/05 (December, January, and February) for 12 locations.

are also close together and located inside the vortex, the angles of their difference-vectors do not always change similarly with time. However, the difference-vectors are predominantly northward, consistent with southward stratopause winds, for both stations. The angles, therefore, differ from those at Scandinavian stations. The difference-vectors at the Poker Flat and Wakkanai locations exhibit their own patterns of angle variations, which have strong northward components, especially at Poker Flat (a more poleward location). The longitudinal variations in the difference-vectors are due to the distortions of the vortex and/or its movement off the pole.

To study the wind variability with periods from 2 to 30 days, the Morlet wavelet (Torrence and Compo, 1998) has been employed. Figure 10 demonstrates examples of wavelet amplitudes of the MetO ( $\sim 50 \mathrm{~km}$, left column) and Radar $(82 \mathrm{~km}$, right column) zonal winds for Svalbard, Troms $\varnothing$, Collm, and Saskatoon (from the top to the bottom). The black line indicates areas with $90 \%$ significance. The three Scandinavian-European stations have similar spectra: long periods ( $>20$ days) in November, short periods (less than 5 days) through out the most of the winter, and energy for periods between 4 and 20 days at the end of February. Clearly there are some differences in exact locations of the peaks as well as their amplitudes, which are smaller at more poleward stations. Some of these differences could be due to different propagation conditions for the $\mathrm{PW}$ at these three stations. As can be seen in Fig. 6, at the end of February the westward background winds are stronger below $50 \mathrm{~km}$ at Svalbard than at Troms $\varnothing$, while over Collm the winds have eastward directions. PW propagation is favored by eastward winds of moderate magnitude (Andrews et al., 1987). Wavelets of MetO zonal winds at Saskatoon have overall smaller amplitudes. Similar to the other stations there is energy at longer periods in November, but in the middle of February there is only one relatively weak peak around 8 days and 10-day maxima appears in the first half of March. This is consistent with the zero wind line and the cell of westward winds at stratospheric heights over, and northward of, Saskatoon (Fig. 5b), which will favor refraction of PW to lower latitudes. The wavelets at the mesospheric heights (the right column) have much smaller amplitudes and do not have many similarities. This variability of local PW activity (latitudinally and longitudinally) is consistent with the earlier study of 16-day PW activity provided by (Luo et al., 2002). In general, compared to previous years, the winter of 2004/05 is characterized by weak planetary wave activity at stratospheric and mesospheric heights.

\section{Summary}

The evolution of the polar vortex during the Arctic winter of 2004/05 has been studied using MetO assimilated fields and data from meteor and MF radars at 12 mid- and high-latitude locations. The winter of 2004/05 was shown to be relatively cold with no major mid-winter stratospheric warmings. MetO parameters near $32 \mathrm{~km}$ averaged over $60^{\circ} \mathrm{N}$ and $70^{\circ} \mathrm{N}$ latitudinal circles exhibit neither rapid temperature increases of $25^{\circ} \mathrm{K}$ or more, nor corresponding reversal of the zonal winds. However there were 3 time intervals with increasing northern temperatures and corresponding weakening of the zonal winds: the end of December/beginning of January, the end of January/beginning of February, and the end of February. During the first two intervals the disturbances were relatively weak. The event at the end of February was the final and strongest disturbance for this winter, and marked the beginning of the wind transition toward summer-like circulation.

During all three disturbed time intervals the stratospheric stationary wave with zonal wave number 1 in MetO temperatures and geopotential heights had enhanced amplitudes. The amplitudes of the temperature wave were the strongest during the last event near $50 \mathrm{~km}$ and, shortly after the beginning of the warming, the lines of constant phase coalesced near $32 \mathrm{~km}$, i.e. there was a very rapid phase change with height. Oscillations (10- and 15-day periods) associated with eastward and westward propagating PW were also present at 

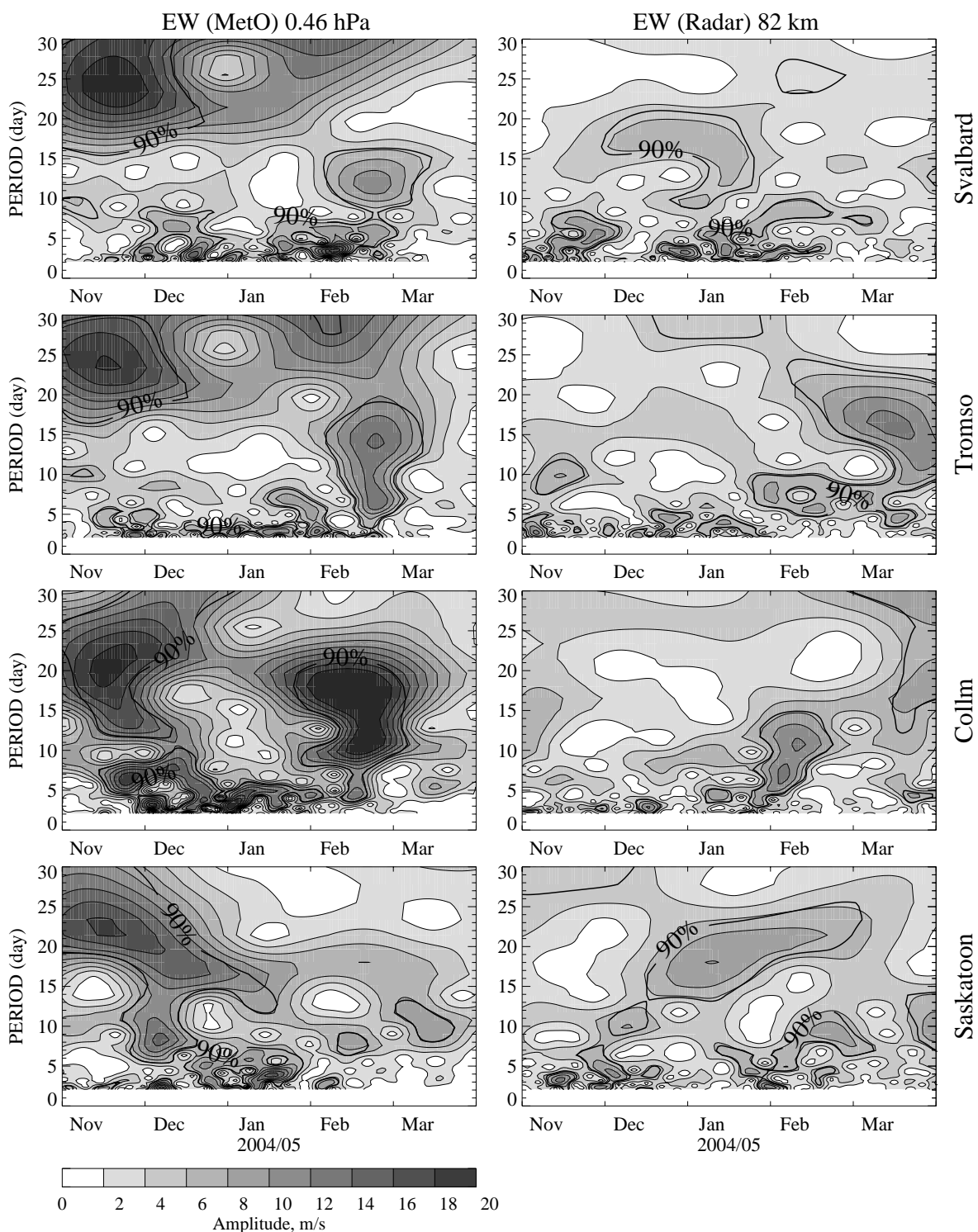

Fig. 10. Wavelet amplitudes versus time (November 2004-March 2005) and period (2-30 days) calculated for the zonal wind component of the MetO winds at $0.46 \mathrm{hPa}$ (left column) and of radar measurements at $82 \mathrm{~km}$ (right column) for the Svalbard, Troms $\varnothing$, Collm, and Saskatoon locations.

upper stratospheric levels. The eastward propagating waves had maxima in the early winter and were confined to the areas with eastward wind flow, consistent with baroclinic waves. The amplitudes of the westward propagating waves (normal modes) increased by the end of winter (February) and were reaching Southern Hemispheric latitudes at upper stratospheric levels in March. Both eastward and westward amplitudes were $\sim 1.5$ times smaller than those calculated for years 2000 and 2001 (Chshyolkova et al., 2006).

To study the longitudinal variations of the polar vortex, the Q-diagnostic was used to characterize the dynamics of the middle and upper stratosphere. The results show that the $\mathrm{NH}$ polar vortex formed in mid-autumn, and was fully estab- lished by 1 December 2004. In December the polar vortex reached its strongest state: it was centered on the pole and occupied a relatively large area. During the three disturbed time intervals the vortex was elongated, slightly shifted off the pole, had a westward tilt with height, and had decreased areas in the lower stratosphere. The deformations were the largest for the last event, when the vortex was divided in two unequal parts below $\sim 600 \mathrm{~K}$ isentropic $(\sim 24 \mathrm{~km})$ level.

The comparison of stratospheric data in the European, North American sectors and Japan revealed significant longitudinal differences during disturbed as well as "quiet" times. In December, for example, the maximum of the eastward wind jet was located $10^{\circ}$ more poleward over Europe (at 
$\sim 50^{\circ} \mathrm{N}$ ) than over North America (at $\sim 40^{\circ} \mathrm{N}$ ). During the late February disturbance the largest differences in the lower and middle stratosphere were between stations located near $50^{\circ} \mathrm{N}$ latitude: Saskatoon $\left(253^{\circ} \mathrm{E}\right)$ and Collm $\left(13^{\circ} \mathrm{E}\right)$. The part of the vortex over Europe was stronger and eastward winds continued to be observed at Collm. In contrast, over Canada winds were westward, as the smaller part of the vortex was practically destroyed and the eastward jet was shifted upward and equatorward. The wavelet amplitudes for the stratospheric $\mathrm{PW}$ oscillations with periods from 2 to 30 days were also remarkably different between European and North American sectors. All stations demonstrated strong activity with periods longer than 20 days in November and an absence of oscillations with periods longer than $\sim 5$ days in the middle of winter. In February, though, wavelet analysis indicated lower PW activity at Saskatoon compared to Collm.

Strong latitudinal differences were also apparent in the zonal wind contour plots and wavelet amplitudes. The eastward winds were systematically weaker and amplitudes of the oscillations associated with PW were smaller at more poleward stations.

Compared to the stratospheric winds, the wavelets of the EW component indicated that the PW had smaller amplitudes and did not show many similarities between stations in the mesosphere. In general, compared to previous years, the winter of 2004/05 could be characterized by weak planetary wave activity at stratospheric and mesospheric heights.

This study suggests that analyses of wind fields at stratospheric and mesospheric heights should not assume that oscillations with periods of days (5-20), which are normally associated with PW activity, exhibit similar amplitude variabilities at all longitudes, i.e. that zonal wave number analysis of global data (model or satellite) for a single mode may produce inaccurate wave characteristics. This variation of PW would be expected when the polar vortex is not centered on the pole and/or is elongated (not circular in shape). Thus this study expands and validates earlier studies (Luo et al., 2002; Manson et al., 2004, 2006) on winter time PW characteristics. A continuation of this study will include chemicals $\left(\mathrm{O}_{3}\right.$, $\mathrm{N}_{2} \mathrm{O}, \mathrm{HCl}$, and $\mathrm{ClO}$ ) from Aura and will illustrate the effects of vortex elongation and displacement. The use of equivalent latitudes (e.g. Manney et al., 2006) helps to deal with vortex displacement issues, but not the elongation. The existence of asymmetry, which results from both of these characteristics, has led to the extreme variability in longitudinal dynamical characteristics shown in this study for 2004/05.

Acknowledgements. The authors would like to express their gratitude to V. L. Harvey and T. D. Fairlie for their help with the Qdiagnostic. T. Chshyolkova is grateful to E. Merzlyakov for his comments. Thanks are due to the Aura team for their MLS dataset as well as to the UK Meteorological Office for the stratospheric assimilated data and to the British Atmosphere Data centre for providing access to these data. The authors are also thankful to the referees for their comments and questions.
Topical Editor U.-P. Hoppe thanks G. G. Shepherd and D. Pancheva for their help in evaluating this paper.

\section{References}

Andrews, D. G., Holton, D. G., and Leovy, C. B.: Middle Atmosphere Dynamics, Academic Press, 489 pp., 1987.

Babiano, A., Boffetta, G., Provenzale, A., and Vulpiani, A.: Chaotic advection in point vortex models and two-dimensional turbulence, Phys. Fluids, 6(7), 2465-2474, doi:10.1063/1.868194, 1994.

Bhattacharya, Y., Shepherd, G. G., and Brown, S.: Variability of atmospheric winds and waves in the Arctic polar mesosphere during a stratospheric sudden warming, Geophys. Res. Lett., 31, L23101, doi:10.1029/2004GL020389, 2004.

Briggs, B. H.: The analysis of spaced sensor records by correlation techniques, in: International Council of Scientific Unions Middle Atmosphere Program, 13, 166-186, 1984.

Cervera, M. A. and Reid, I. M.: Comparison of simultaneous wind measurements using collocated VHF meteor radar and MF spaced antenna radar systems, Radio Sci., 30(4), 1245-1262, 1995.

Chshyolkova, T., Manson, A. H., Meek, C. E., Avery, S. K., Thorsen, D., MacDougall, J. W., Hocking, W., Murayama, Y., and Igarashi, K.: Planetary wave coupling in the middle atmosphere (20-90 km): A study involving TOMS, MetO and MF radar data, Ann. Geophys., 23, 1103-1131, 2005, http://www.ann-geophys.net/23/1103/2005/.

Chshyolkova, T., Manson, A. H., Meek, C. E., Avery, S. K., Thorsen, D., MacDougall, J. W., Hocking, W., Murayama, Y., and Igarashi, K.: Planetary wave coupling processes in the middle atmosphere (30-90 km): A study involving MetO and MFR data, J. Atmos. Solar-Terr. Phys., 68(3-5), 353-368, 2006.

Fairlie, T. D. A.: Three-dimensional transport simulations of the dispersal of volcanic aerosol from Mount Pinatubo, Quart. J. Roy. Meteorol. Soc., 121(528), 1943-1980, doi:10.1256/smsqj.52808, 1995.

Froidevaux, L., Livesey, N. J., Read, W. G., Jiang, Y. B, Jimenez, C. C., Filipiak, M. J., Schwartz, M. J., Santee, M. L., Pumphrey, H. C., and Jiang, J. H.: Early validation analyses of atmospheric profiles from EOS MLS on the Aura satellite, IEICE T. Commun., 44(5), 1106-1121, 2006.

Gregory, J. B. and Manson, A. H.: Winds and wave motions to $110 \mathrm{~km}$ at mid-latitudes. III Response of mesospheric and thermospheric winds to major stratospheric warmings, J. Atmos. Sci., 32(9), 1676-1681, 1975.

Greisiger, K. M., Portnyagin, Y. I., and Lyssenko, I. A.: Largescale winter-time disturbances in meteor winds over Central and Eastern Europe and their connection with processes in the stratosphere, J. Atmos. Terr. Phys., 46(4), 389-394, 1984.

Hall, C.: The Ramfjordmoen MF radar $\left(69^{\circ} \mathrm{N}, 19^{\circ} \mathrm{E}\right)$ : application development 1990-2000, J. Atmos. Solar-Terr. Phys., 63(2-3), 171-179, 2001.

Hall, C. M., Aso, T., Manson, A. H., Meek, C. E., Nozawa, S., and Tsutsumi, M.: High-latitude mesospheric mean winds: A comparison between Troms $\varnothing(69 \mathrm{~N})$ and Svalbard (78 N), J. Geophys. Res., 108(D19), 4598, doi:10.1029/2003JD003509, 2003.

Hall, C. M., Aso, T., Tsutsumi, M., Nozawa, S., Manson, A., and Meek, C. E.: A comparison of mesosphere and 
lower thermosphere neutral winds as determined by meteor and medium-frequency radar at $70^{\circ} \mathrm{N}$, Radio Sci., 40(4), RS4001, doi:10.1029/2004RS003102, 2005.

Harvey, V. L., Pierce, R. B., Fairlie, T. D., and Hitchman, M. H.: A climatology of stratospheric polar vortices and anticyclones, J. Geophys. Res., 107(D20), 4442, doi:10.1029/2001JD001471, 2002.

Hocking, W. K., Fuller, B., and Vandepeer, B.: Real-time determination of meteor-related parameters utilizing modern digital technology, J. Atmos. Solar-Terr. Phys., 63(2-3), 155-169, 2001.

Hocking, W. K.: Experimental Radar Studies of Anisotropic Diffusion of High Altitude Meteor Trails, Earth Moon Planets, 95(1), 671-679, 2004.

Hoffmann, P., Singer, W., and Keuer, D.: Variability of the mesospheric wind field at middle and Arctic latitudes in winter and its relation to stratospheric circulation disturbances, J. Atmos. Solar-Terr. Phys., 64(8-11), 1229-1240, 2002.

Holton, J. R.: The Influence of Gravity-Wave Breaking on the General-Circulation of the Middle Atmosphere, J. Atmos. Sci., 40(10), 2497-2507, 1983.

Jacobi, C., Schminder, R., and Kürschner, D.: The winter mesopause wind field over Central Europe and its response to stratospheric warmings as measured by LF D1 wind measurements at Collm, Germany, Adv. Space Res., 20(6), 1223-1226, 1997.

Jacobi, C., Kürschner, D., Muller, H. G., Pancheva, D., Mitchell, N. J., and Naujokat, B.: Response of the mesopause region dynamics to the February 2001 stratospheric warming, J. Atmos. Solar-Terr. Phys., 65(7), 843-855, 2003.

Jacobi, C., Kürschner, D., Fröhlich, K., Arnold, K., and Tetzlaff, G.: Meteor radar wind and temperature measurements over Collm $(51.3 \mathrm{~N}, 13 \mathrm{E})$ and comparison with co-located LF drift measurements during autumn 2004, Reports Inst. Meteorol. Univ. Leipzig, 36, 98-112, 2005.

Jiménez, C., Pumphrey, H. C., MacKenzie, I. A., Manney, G. L., Santee, M. L., Schwartz, M. J., Harwood, R. S., and Waters, J. W.: EOS MLS observations of dehydration in the 2004-2005 polar winters, Geophys. Res. Lett., 33(16), L16806, doi:10.1029/2006GL025926, 2006.

Labitzke, K.: Temperature changes in the mesosphere and stratosphere connected with circulation changes in winter, J. Atmos. Sci., 29(4), 756-766, 1972.

Lindzen, R. S.: Turbulence and stress owing to gravity wave and tidal breakdown, J. Geophys. Res., 86, 9707-9714, 1981.

Liu, H. L. and Roble, R. G.: A study of a self-generated stratospheric sudden warming and its mesospheric-lower thermospheric impacts using the coupled TIME-GCM/CCM3, J. Geophys. Res., 107(D23), 4695, doi:10.1029/2001JD001533, 2002.

Lorenc, A. C., Ballard, S. P., Bell, R. S., Ingleby, N. B., Andrews, P. L. F., Barker, D. M., Bray, J. R., Clayton, A. M., Dalby, T., Li, D., Payne, T. J., and Saunders, F. W.: The Met. Office global three-dimensional variational data assimilation scheme, Quart. J. Roy. Meteorol. Soc., Part B, 126(570), 2991-3012, 2000.

Luo, Y., Manson, A. H., Meek, C. E., Meyer, C. K. Burrage, M. D., Fritts, D. C., Hall, C. M., Hocking, W. K., MacDougall, J., Riggin, D. M., and Vincent, R. A.: The 16-day planetary waves: multi-MF radar observations from the arctic to equator and comparisons with the HRDI measurements and the GSWM modelling results, Ann. Geophys., 20, 691-709, 2002, http://www.ann-geophys.net/20/691/2002/.

Manney, G. L., Santee, M. L., Froidevaux, L., Hoppel, K., Livesey, N. J., and Waters, J. W.: EOS MLS observations of ozone loss in the 2004-2005 Arctic winter, Geophys. Res. Lett., 33(4), L04802, doi:10.1029/2005GL024494, 2006.

Manson, A. H., Gregory, J. B., and Stephenson, D. G.: Winds and wave motions $/ 70-100 \mathrm{~km} /$ as measured by a partial reflection radiowave system, J. Atmos. Terr. Phys., 35, 2055-2067, 1973.

Manson, A. H., Meek, C. E., Fleming, E., Chandra, S., Vincent, R. A., Phillips, A., Avery, S. K., Fraser, G. J., Smith M. J., and Fellous, J. L.: Comparisons between Satellite-derived Gradient Winds and Radar-derived Winds from the CIRA-86, J. Atmos. Sci., 48(3), 411-428, 1991.

Manson, A. H., Meek, C. E., Stegman, J., Espy, P. J., Roble, R. G., Hall, C. M., Hoffmann, P., and Jacobi, Ch.: Springtime transition in mesopause airglow and dynamics: photometer and MF Radar observations in the Scandinavian and Canadian sectors, J. Atmos. Solar-Terr. Phys. 64, 1131-1146, 2002.

Manson, A. H., Meek, C. E., Avery, S. K., and Thorsen, D.: Ionospheric and dynamical characteristics of the mesosphere-lower thermosphere region over Platteville $\left(40^{\circ} \mathrm{N}, 105^{\circ} \mathrm{W}\right)$ and comparisons with the region over Saskatoon $\left(52^{\circ} \mathrm{N}, 107^{\circ} \mathrm{W}\right)$, J. Geophys. Res., 108(D13), 4398, doi:10.1029/2002JD002835, 2003.

Manson, A. H., Meek, C. E., Chshyolkova, T., Avery, S. K., Thorsen, D., MacDougall, J. W., Hocking, W., Murayama, Y., Igarashi, K., Namboothiri, S. P., and Kishore, P.: Longitudinal and latitudinal variations in dynamic characteristics of the MLT (70-95 km): a study involving the CUJO network, Ann. Geophys., 22, 347-365, 2004,

http://www.ann-geophys.net/22/347/2004/.

Manson, A. H., Meek, C. E., Chshyolkova, T., McLandress, C., Avery, S. K., Fritts, D. C., Hall, C. M., Hocking, W. K., Igarashi, K., MacDougall, J. W., Murayama, Y., Riggin, D. C., Thorsen, D., and Vincent, R. A.: Winter warmings, tides and planetary waves: comparisons between CMAM (with interactive chemistry) and MFR-MetO observations and data, Ann. Geophys., 24, 24932518, 2006, http://www.ann-geophys.net/24/2493/2006/.

Matsuno, T.: A Dynamical Model of the Stratospheric Sudden Warming. J. Atmos. Sci., 28(8), 1479-1494, 1971.

Meek, C. E.: An efficient method for analysing ionospheric drifts data, J. Atmos. Terr. Phys., 42, 835-839, 1980.

Mitchell, N. J., Pancheva, D., Middleton, H. R., and Hagan, M. E.: Mean winds and tides in the Arctic mesosphere and lower thermosphere, J. Geophys. Res., 107(A1), 1004, doi:10.1029/2001JA900127, 2002.

Müller, R. and Günther, G.: A generalized form of Lait's modified potential vorticity, J. Atmos. Sci., 60(17), 2229-2237, 2003.

Müller, R. and Günther, G.: Polytropic atmospheres and the scaling of potential vorticity, Meteorol. Atmos. Phys., 90(3-4), 153-157, 2005.

Murayama, Y., Igarashi, K., Rice, D. D., Watkins, B. J., Collins, R. L., Mizutani, K., Saito, Y., and Kainuma, S.: Medium frequency radars in Japan and Alaska for upper atmosphere observations, IEICE T. Commun., E83-B(9), 1996-2003, 2000.

O’Neill, A., Grose, W. L., Pope, V. D., Maclean, H., and Swinbank, R.: Evolution of the Stratosphere during Northern Winter 1991/92 as Diagnosed from UK-Meteorological-Office Analyses, J. Atmos. Sci., 51(20), 2800-2817, 1994. 
Portnyagin, Yu. I., Merzlyakov, E. G., Solovjova, T. V., Jacobi, Ch., Kürschner, D., Manson, A., and Meek, C.: Long-term trends and year-to-year variability of mid-latitude mesosphere/lower thermosphere winds, J. Atmos. Solar-Terr. Phys., 68, 1890-1901, 2006.

Randel, W., Udelhofen, P., Fleming, E., Geller, M., Gelman, M., Hamilton, K., Karoly, D., Ortland, D., Pawson, S., Swinbank, R., Wu, F., Baldwin M., Chanin, M.-L., Keckhut, P., Labitzke, K., Remsberg, E., Simmons, A., and Wu, D.: The SPARC intercomparison of middle-atmosphere climatologies, J. Climate, 17(5), 986-1003, 2004.

Schoeberl, M. R. and Hartmann, D. L.: The Dynamics of the Stratospheric Polar Vortex and its Relation to Springtime Ozone Depletions, Science, 251(4989), 46-52, 1991.

Shepherd, T. G.: The middle atmosphere, J. Atmos. Solar-Terr. Phys., 62(17-18), 1587-1601, 2000.

Singer, W., Keuer, D., and Eriksen, W.: The ALOMAR MF Radar: Technical Design and First Results, European Rocket and Balloon Programmes and Related Research, Proceedings of the 13th ESA Symposium held 26-29 May, 1997 in Öland, Sweden, 2629 May, 1997.

Smith, M. J., Gregory, J. B., Manson, A. H., Meek, C. E., Schminder, R., Kürschner, D., and Labitzke, K.: Responses of the upper middle atmosphere $(60-110 \mathrm{~km})$ to the stratwarms of the four pre-map winters (1978/9-1981/2), Adv. Space Res., 2(10), 173-176, 1982.
Smith, A. K.: Longitudinal variations in mesospheric winds: evidence for gravity wave filtering by planetary waves, J. Atmos. Sci, 53, 1156-1173, 1996.

Thayaparan, T., Hocking, W. K., and MacDougall, J.: Middle atmospheric winds and tides over London, Canada $\left(43^{\circ} \mathrm{N}, 81^{\circ} \mathrm{W}\right)$ during 1992-1993, Radio Sci., 30(4), 1293-1309, 1995.

Thayaparan, T. and Hocking, W. K.: A long-term comparison of winds and tides measured at London, Canada $\left(43^{\circ} \mathrm{N}, 81^{\circ} \mathrm{W}\right)$ by co-located MF and meteor radars during 1994-1999, J. Atmos. Solar-Terr. Phys., 64(8-11), 931-946, 2002.

Torrence, C. and Compo, G. P.: A practical guide to wavelet analysis, B. Am. Meteorol. Soc., 79(1), 61-78, 1998.

Wallace, J. M. and Hobbs, P. V.: Atmospheric science: an introductory survey, 2nd ed., Elsevier Inc, 483 pp., 2006.

Waters, J. W., Froidevaux, L., Harwood, R. S., Jarnot, R. F., Pickett, H. M., Read, W. G., Siegel, P. H., Cofield, R. E., Filipiak, M. J., and Flower, D. A.: The Earth Observing System Microwave Limb Sounder (EOS MLS) on the Aura satellite, IEEE T. Geosci. Remote, 44(5), 1075-1092, 2006. 